\title{
SCF AND CULLIN/RING H2-BASED UBIQUITIN LIGASES
}

\author{
R. J. Deshaies \\ Department of Biology 156-29, California Institute of Technology, Pasadena, California \\ 91125,deshaies@cco.caltech.edu
}

Key Words ubiquitin, ubiquitination, F box, Skp1, Cdc34

Abstract Protein degradation is deployed to modulate the steady-state abundance of proteins and to switch cellular regulatory circuits from one state to another by abrupt elimination of control proteins. In eukaryotes, the bulk of the protein degradation that occurs in the cytoplasm and nucleus is carried out by the $26 \mathrm{~S}$ proteasome. In turn, most proteins are thought to be targeted to the $26 \mathrm{~S}$ proteasome by covalent attachment of a multiubiquitin chain. Ubiquitination of proteins requires a multienzyme system. A key component of ubiquitination pathways, the ubiquitin ligase, controls both the specificity and timing of substrate ubiquitination. This review is focused on a conserved ubiquitin ligase complex known as SCF that plays a key role in marking a variety of regulatory proteins for destruction by the $26 \mathrm{~S}$ proteasome.

\section{CONTENTS}

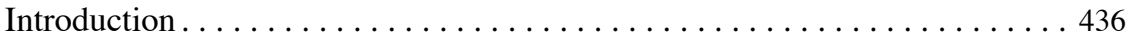

Identification of SCF Ubiquitin Ligase Activity . . . . . . . . . . . . 437

Subunits of SCF . . . . . . . . . . . . . . . . . . . . . . . . . 439

Architecture of SCF Complexes and SCF Pathway Components . . . . . . . 439

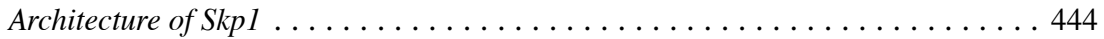

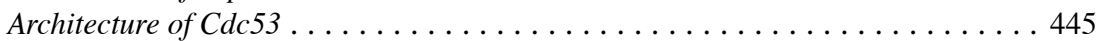

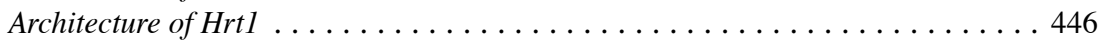

Architecture of F Box Proteins . . . . . . . . . . . . . . . . . . 446

Architecture of F Box Proteins: Cdc4 . . . . . . . . . . . . . . . . . . . . 447

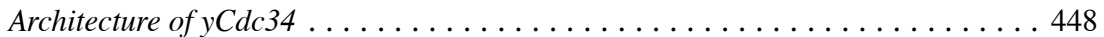

Post-Translational Control of SCF Pathway Components . . . . . . . . . . . . . 448

Post-Translational Regulation of Skpl . . . . . . . . . . . . . . . . . . . . . . . 449

Post-Translational Regulation of Cdc53/Cullin . . . . . . . . . . . . . . . . . . 449

Post-Translational Regulation of Hrt1 . . . . . . . . . . . . . . . . . 450

Post-Translational Regulation of F Box Proteins . . . . . . . . . . . . . . . 450

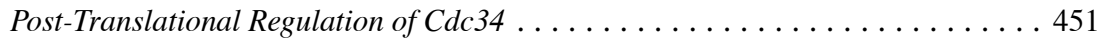

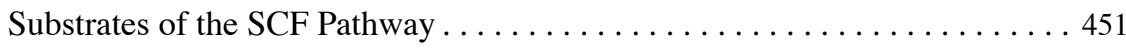

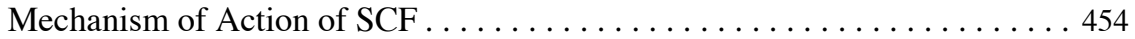


How Does Substrate Bind SCF? . . . . . . . . . . . . . . . . . . 454

How is Ubiquitin Transferred From Cdc34 to Substrate? . . . . . . . . . . . . . . 455

How Does SCF Promote the Assembly of a Multiubiquitin Chain? . . . . . . . . . 456

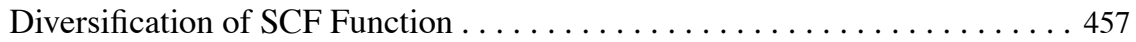

The F Box Hypothesis . . . . . . . . . . . . . . . . . . . . . . . . 457

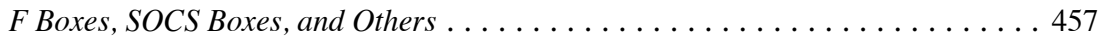

Conclusion and Perspectives . . . . . . . . . . . . . . . . . 459

\section{INTRODUCTION}

Proteolysis in the eukaryotic cytosol typically involves the assembly of a substratelinked ubiquitin chain, which targets specific proteins for degradation by the $26 \mathrm{~S}$ proteasome (Hochstrasser 1995). Ubiquitin is activated for transfer to substrate through the ATP-dependent formation of a thioester bond with the ubiquitinactivating enzyme, E1. Ubiquitin is subsequently transferred to a member of a family of ubiquitin-conjugating (E2) enzymes. Finally, thioesterified ubiquitin is transferred from E2 enzyme to a lysine residue of the target protein, either directly or with the assistance of a ubiquitin ligase (E3). E3s bind directly to substrate, suggesting that they provide specificity in ubiquitination reactions. One well-characterized E3, known as E6-AP, also forms a thioester with ubiquitin as an intermediate in the transfer of ubiquitin from E2 to substrate (Scheffner et al 1995). Because E3s dictate the specificity of ubiquitination reactions, it is likely that protein degradation in vivo is controlled primarily by regulating E3 activity or E3-substrate interaction.

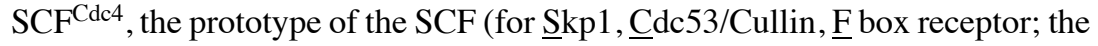
superscript denotes the identity of the F box subunit) family of ubiquitin ligases, was first defined in budding yeast by in vitro reconstitution (Feldman et al 1997, Skowyra et al 1997). Over the past few years, SCF pathway components have been identified and linked to diverse cellular processes in many eukaryotes. In this review, I describe the multiple lines of research that led to the discovery of SCF ubiquitin ligases and review what is known about the subunits, architecture, regulation, substrates, mechanism of action, and functional diversification of SCF complexes. Several excellent reviews focused on various roles of the SCF complex have been published recently (Elledge \& Harper 1998, Krek 1998, Patton et al 1998a). It is the goal of this article to provide a comprehensive review of current knowledge. The SCF pathway was originally discovered in the budding yeast Saccharomyces cerevisiae and has been most thoroughly characterized in this organism. For the sake of simplicity, this review concentrates on budding yeast SCF, but draws extensively on the rapidly expanding literature on mammalian SCF to supplement the findings that have emerged from study of yeast SCF. In instances where budding yeast and human SCF subunits have the same name, the protein is preceded by either $\mathrm{y}$ or $\mathrm{h}$ to indicate the organism from which the protein is derived. 


\section{IDENTIFICATION OF SCF UBIQUITIN LIGASE ACTIVITY}

Identification of the $\mathrm{SCF}^{\mathrm{Cdc} 4}$ ubiquitin ligase complex stemmed from a genetic analysis of the G1/S transition by Schwob et al (1994). These authors demonstrated that budding yeast $c d c 4^{t s}, c d c 34^{t s}$, and $c d c 53^{t s}$ mutants fail to enter $\mathrm{S}$ phase because they are unable to eliminate the $\mathrm{S}$ phase cyclin/cyclin-dependent kinase (CDK) inhibitor Sic1. Sic 1 is normally destroyed as wild-type cells progress from $\mathrm{G} 1$ to $\mathrm{S}$ phase but persists indefinitely in the $c d c$ mutants. Subsequently, it was shown that skpl ${ }^{t s}$ mutants have a similar phenotype (Bai et al 1996). yCdc34 was a logical candidate for a Sic1 destabilizing factor because it possesses ubiquitin-conjugating enzyme activity (Goebl et al 1988). In contrast, although genetic analysis suggested a role for $\mathrm{Cdc} 4, \mathrm{Cdc53}$, and Skp1 in Sic1 degradation, it was unclear what these proteins might be doing, as they bore no resemblance to any known component of ubiquitin-dependent proteolytic pathways.

The components of the SCF pathway were discovered and characterized in several laboratories. $c d c 4^{t s}$ and $c d c 34^{t s}$ mutants were identified in screens for cell cycle mutants by Hartwell and colleagues (Pringle \& Hartwell 1981), and the corresponding genes were cloned by complementation of the $t s$ mutants (Goebl et al 1988, Peterson et al 1984). The $c d c 53^{t s}$ mutant was identified in a screen for mutants with a $c d c 34^{t s}$-like phenotype, and $C D C 53$ was cloned by complementation of this mutant (Mathias et al 1996). The sequence of Cdc53 revealed that it is homologous to a family of proteins called cullins. The first reported cullin, cul-1, was identified in nematodes as a gene required for developmentally programmed transitions from G1 phase of the cell cycle to G0 phase (Kipreos et al 1996). Cdc53 and Cdc4 were shown to coprecipitate from yeast cell lysates with Cdc34, suggesting that these proteins directly participate in protein ubiquitination (Mathias et al 1996). Cdc53 was independently identified as a protein that copurified with the unstable G1 cyclin Cln2 (Willems et al 1996). These authors demonstrated that Cdc53 binds $\mathrm{Cln} 2$ and that $c d c 53^{\text {ts }}$ mutants are defective in Cln2 turnover. Lastly, ySKP1 was identified in a screen for genes that suppress $c d c 4^{t s}$ mutants upon overexpression (Bai et al 1996). This screen also revealed the gene that encodes human cyclin F (Bai et al 1994). ySkp1 was also identified by Connelly \& Hieter (1996) as a component of the centromere-binding CBF3 complex. The human orthologue of ySkp1 had previously been identified as a cyclin A/CDK2-associated protein, but its biochemical function was not known (Zhang et al 1995). Remarkably, the otherwise dissimilar Cdc4 and human cyclin F proteins were shown to share a small sequence motif designated the F box (Bai et al 1996). The F box, which is found in a large number of proteins, mediates binding of both $\mathrm{Cdc} 4$ and cyclin $\mathrm{F}$ to ySkp1.

The final discovery key to identification of SCF ubiquitin ligase stemmed from biochemical reconstitution of Sic1 ubiquitination. First, ubiquitination of Sic1 in crude yeast extracts was shown to depend upon yCdc34, Cdc4, and G1 cyclin/CDK 
activity (Verma et al 1997b). These data suggested that the role identified for these proteins in Sic1 turnover in vivo (Schneider et al 1996, Schwob et al 1994) was likely to be direct. Skowyra et al (1997) and Feldman et al (1997) next demonstrated that Cdc4, Cdc53, and ySkp1 expressed in insect cells assemble into a complex and that the purified complex functions as a ubiquitin ligase, promoting ubiquitination of phosphorylated Sic1 by the yCdc34 ubiquitin-conjugating enzyme. Skowyra et al (1997) also demonstrated that a distinct SCF complex can be formed by replacing Cdc4 with another F box-containing protein, Grr1. This important finding suggested that $\mathrm{SCF}^{\mathrm{Cdc} 4}$ may be the prototype for a broad array of SCF-like ubiquitin ligases whose substrate specificity is dictated by the identity of the F box subunit (see DIVERSIFICATION OF SCF FUNCTION for a detailed discussion). In parallel with the reconstitution efforts, phosphorylation of Sic1 on a set of CDK consensus sites was shown to be necessary and sufficient to trigger its ubiquitination in vitro and degradation in vivo (Verma et al 1997a). Taken together, the results demonstrate that the G1/S transition in budding yeast is triggered by the phosphorylation of Sic1 by G1 cyclin/CDK, followed by the ubiquitination of phosphorylated Sic1 through the combined efforts of $\mathrm{SCF}^{\mathrm{Cdc} 4}$ and $\mathrm{yCdc} 34$.

Very recently, a fourth essential subunit of SCF, referred to as Roc1, Rbx1, or Hrt1, was reported (Kamura et al 1999, Ohta et al 1999, Seol et al 1999, Tan et al 1999). Throughout the remainder of this review I refer to the mammalian versions of this protein as Roc $1 / \mathrm{Rbx} 1$ and to the highly homologous budding yeast version as Hrt1. This new protein was identified as a fourth subunit of $\mathrm{SCF}^{\mathrm{SKP} 2}$ complexes purified from HeLa cells (Tan et al 1999), as a hCul1-binding protein in a twohybrid screen (Ohta et al 1999), as a fifth subunit of purified rat VHL/elongin C/elongin B/Cul2 complexes (Kamura et al 1999), and as a specific component of ySkp1 and Cdc53 immunoprecipitates (Seol et al 1999). Roc1/Rbx1/Hrt1 is homologous to the Apc11 subunit of the Anaphase-Promoting Complex/Cyclosome (APC/C) (Zachariae et al 1998), and shares with both yeast and human Apc11 a highly conserved zinc-binding RING-H2 domain.

Budding yeast $H R T l$ is essential, and the lethal phenotype of an $h r t l \Delta$ allele can be rescued by the highly homologous murine or human ROC1/RBXI (Kamura et al 1999, Ohta et al 1999, Seol et al 1999). Analysis of Hrt1-depleted cells and hrt ${ }^{\text {ts }}$ mutants revealed that turnover of the SCF substrates Sic1 and Cln2 requires HRT1 function, resulting in accumulation of these proteins in mutant cells (Kamura et al 1999, Ohta et al 1999, Seol et al 1999). Hrt1 is also important for SCF function in vitro in that recombinant Hrt1 dramatically stimulates the ability of $\mathrm{SCF}$ to ubiquitinate $\mathrm{C} \ln 1, \mathrm{Cln} 2$, $\mathrm{Sic} 1$, and $\mathrm{I} \kappa \mathrm{B}$, as well as to assemble unanchored multiubiquitin chains and promote autoubiquitination of yCdc34 (Kamura et al 1999, Ohta et al 1999, Seol et al 1999, Skowyra et al 1999, Tan et al 1999). These observations provoke a simple question - Why did the original reconstitution of $\mathrm{SCF}^{\mathrm{Cdc} 4}$ work in the absence of Hrt1 (Feldman et al 1997, Skowyra et al 1997)? Given the high degree of structural and functional conservation of this protein, it is likely that recombinant SCF complexes produced with the baculovirus system incorporate an insect homolog of Hrt1. Assembly of active SCF complexes with 
subunits from different species has been noted before (Feldman et al 1997, Lyapina et al 1998).

\section{SUBUNITS OF SCF}

Many putative SCF subunits, including a large number of $\mathrm{F}$ box proteins, have been identified in eukaryotes by database searches, genetic screens, and two-hybrid screens. These proteins contribute to a broad spectrum of cellular activities ranging from the auxin response in plants, withdrawal from the cell cycle in nematodes, entry into $\mathrm{S}$ phase and $\mathrm{M}$ phase of the cell cycle in budding yeast, signaling via the Wnt and hedgehog pathways in Drosophila and Xenopus, and innate immunity in human cells. Rather than discuss each of these proteins in detail, the basic properties of those that have been described in the literature are summarized in Table 1. It is important to note that most of these proteins have not been confirmed to be members of functional ubiquitin ligase complexes. This may be especially critical for the $\mathrm{F}$ box proteins, since at least one known $\mathrm{F}$ box protein ( $\mathrm{Ctf13}$ ) appears to function primarily as a component of the budding yeast kinetochore (Connelly \& Hieter 1996, Kaplan et al 1997, Stemmann \& Lechner 1996).

\section{ARCHITECTURE OF SCF COMPLEXES AND SCF PATHWAY COMPONENTS}

The four subunits of $\mathrm{SCF}^{\mathrm{Cdc} 4}$ assemble together to form a heterotetrameric ubiquitin ligase (Figure 1). Within this complex, the $\mathrm{F}$ box-containing $\mathrm{Cdc} 4$ subunit directly binds substrate, the Cdc53 and Hrt1 subunits recruit the Cdc34 ubiquitinconjugating enzyme, and Skp1 helps to link the Cdc4 and Cdc53 subunits (Feldman et al 1997, Skowyra et al 1997, Willems et al 1996, Patton et al 1998, Seol et al 1999, Skowra et al 1999). Together, these four subunits make up the minimal SCF ubiquitin ligase complex. Affinity purification of SCF complexes from budding yeast suggests that other proteins associate with ySkp1 and Cdc53 (JH Seol, personal communication), but it remains unclear whether these represent substrates, proteins restricted to specific SCF complexes, components of multisubunit F box receptors, or uncharacterized members of the core complex.

In the following sections, the domain organization and properties of each SCF subunit and how they contribute to the architecture of the complex are discussed (see Figure 2 for a summary of the structural organization of Skp1, Cdc53, Hrt1, and Cdc34). All known SCF subunits are highly conserved throughout eukaryotes. As evidence of the functional conservation of these proteins, $h S K P 1, h C U L 1$, and $R O C 1 / R B X 1$ have been shown to complement the corresponding budding yeast mutants and can assemble with yeast SCF subunits to form active complexes (Bai et al 1996, Lyapina et al 1998, Kamura et al 1999, Ohta et al 1999, Seol et al 1999, Skowyra et al 1999). Thus unless interactions between recombinant SCF subunits 


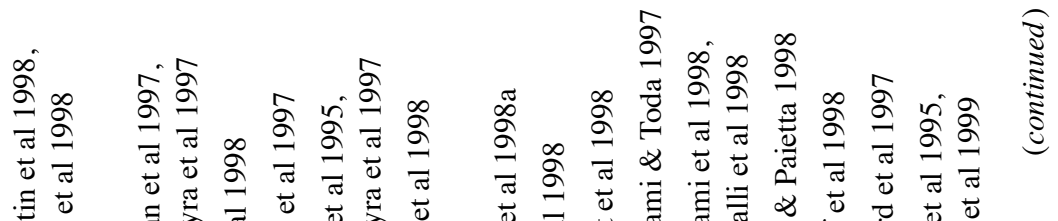

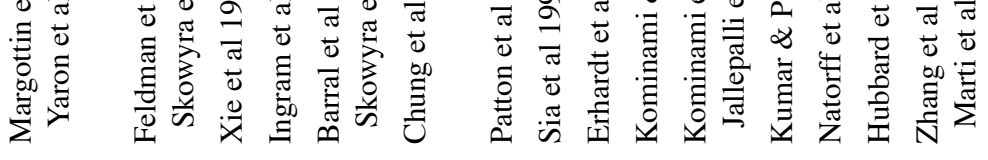

氖

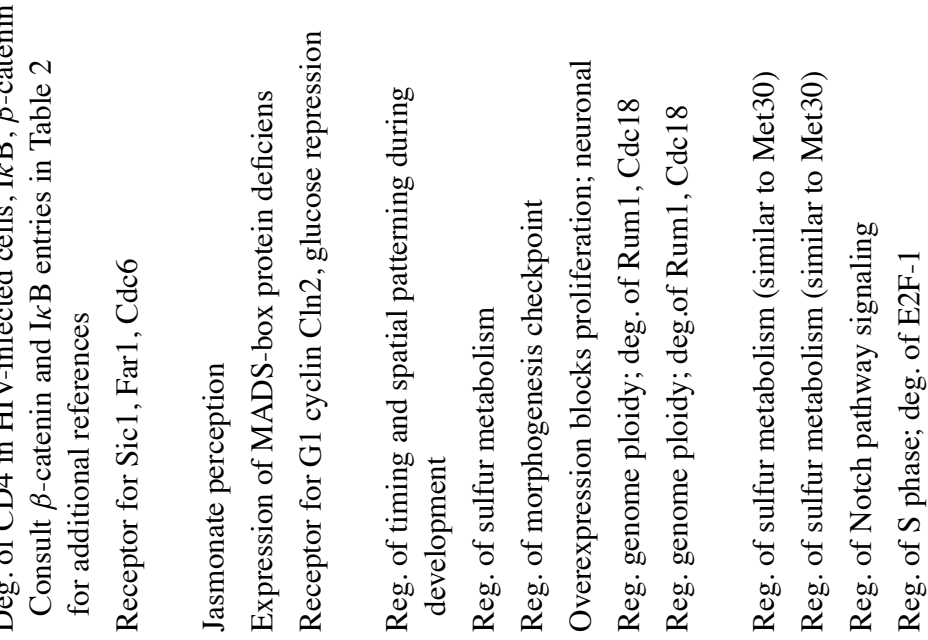

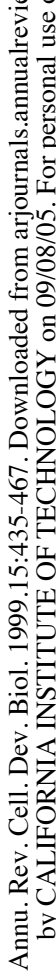

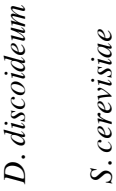

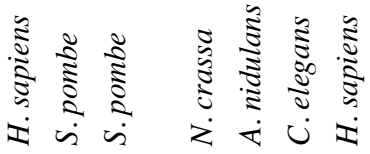

:

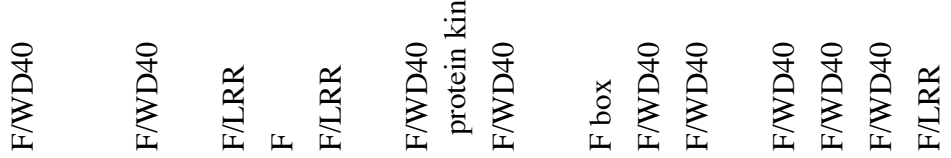

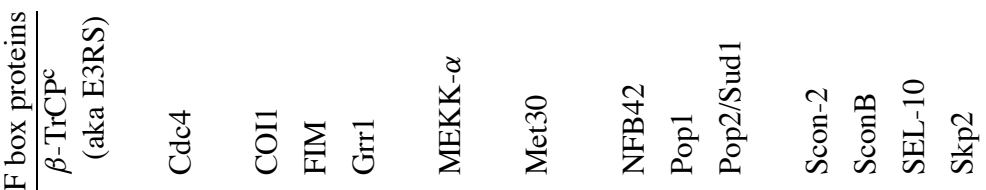




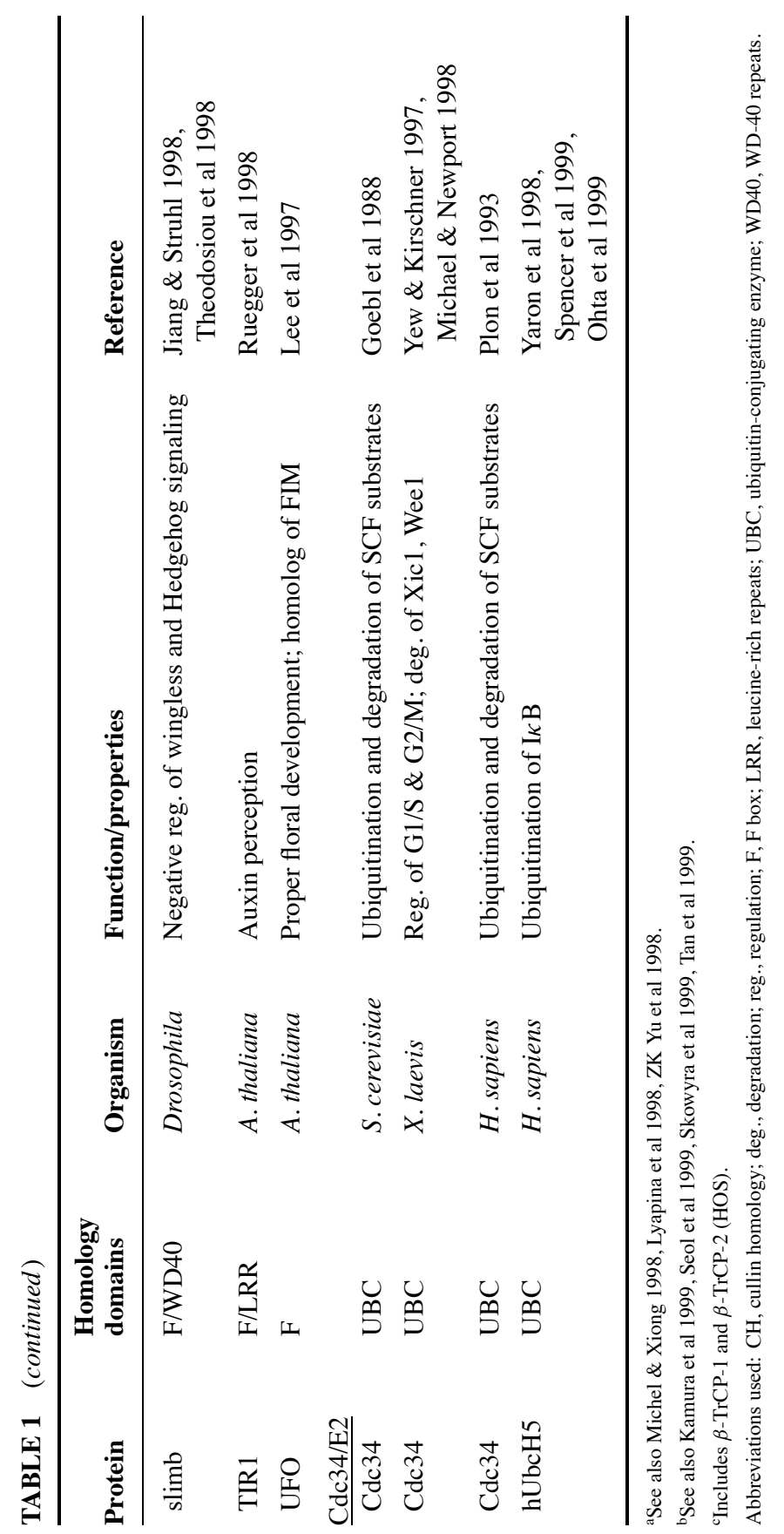




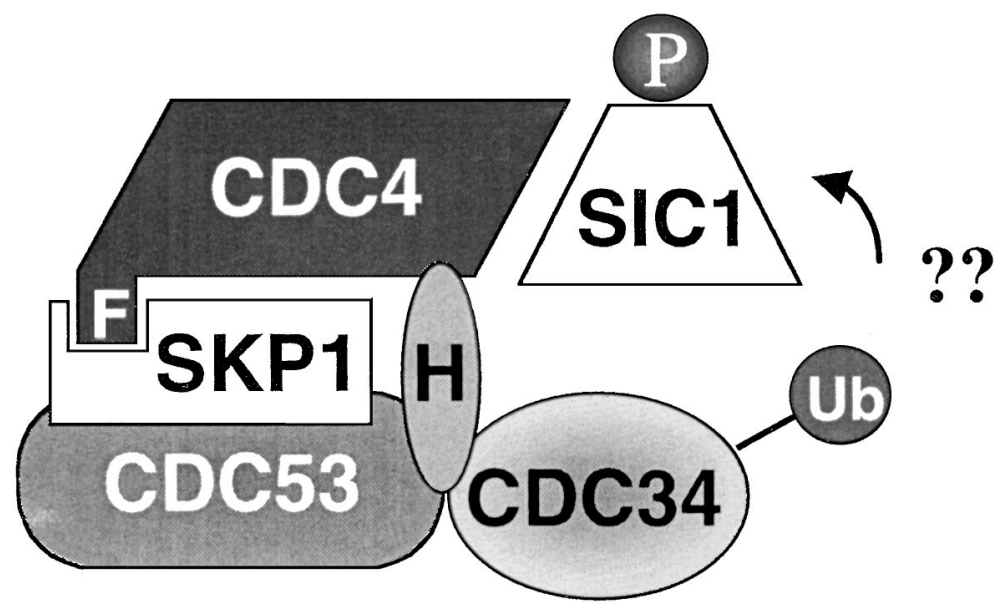

Figure 1 Anatomy of the $\mathrm{SCF}^{\mathrm{Cdc} 4}$ complex. The figure summarizes what is known about protein-protein interactions in the $\mathrm{SCF}^{\mathrm{Cdc} 4}$ complex. Sic1 binds to $\mathrm{Cdc} 4$ only when it is phosphorylated. By analogy to the interaction of $\beta$-TrCP with $\mathrm{I} \kappa \mathrm{B}$ (Yaron et al 1998), it is likely that the phosphate groups on Sic1 directly serve as part of the ligand that contacts $\mathrm{Cdc} 4$. The mechanism by which ubiquitin is transferred from Cdc34 to substrate is not understood. H, Hrt1; F, F box.
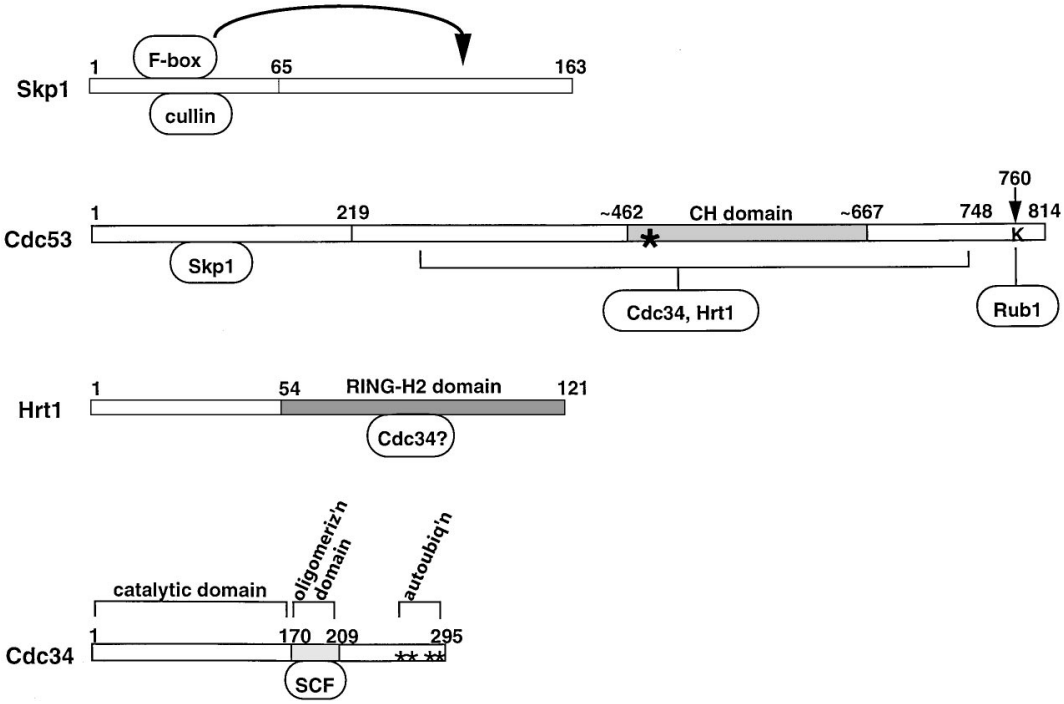

Figure 2 Domain organization of SCF subunits. See text for details. Numbers above each protein refer to positions in the amino acid sequence. The arrow in the Skp1 diagram is intended to convey the notion that $\mathrm{F}$ boxes bind to the $\mathrm{N}$-terminal domain of Skp1 but that the interaction is stabilized by the C-terminal domain. The asterisk in the Cdc53 diagram indicates the position of the $c d c 53-1$ mutation and the arrow marks the site of attachment of Rub1. The asterisks in the Cdc34 diagram refer to the positions of four lysine residues that are targets of autoubiquitination. 
are tested with highly purified proteins or proteins isolated from a prokaryotic source, it is difficult to exclude the possibility that the interaction involves other proteins (or post-translational modifications) common to eukaryotic cells.

\section{Architecture of Skp1}

Multiple F box-containing proteins have been shown to bind Skp1, and the human $\mathrm{F}$ box protein Skp2 binds to hSkp1 upon expression of both proteins in bacteria, indicating that the interaction is direct (Yam et al 1999). Skp1 binds Cdc53/hCul1 upon expression of both proteins in either insect cells (Skowyra et al 1997) or Escherichia coli (Lyapina et al 1998), indicating that these two subunits also interact directly.

Sequence comparisons and deletion analyses suggest that hSkp1 is divided into two domains: an $\sim 110$ amino acid N-terminal domain related to elongin $\mathrm{C}$ and an $\sim 53$ amino acid unique C-terminal domain (ySkp1 contains a 30 amino acid insertion within the $\mathrm{N}$-terminal domain, but $s k p 1^{t s}$ mutants are nonetheless complemented by $h S K P 1)$. Amino acids 1-91 of hSkp1 [i.e. hSkp1(1-91)] bind hCul1 in a two-hybrid assay (Michel \& Xiong 1998). Likewise, hSkp1(37-163) and hSkp1(1-65) bind the F box protein Skp2 with 15 to $20 \%$ the efficiency of full-length hSkp1, respectively ( $\mathrm{Ng}$ et al 1998). Taken together, these data suggest that the first 91 residues of hSkp1 contain both an $\mathrm{F}$ box-binding determinant and a cullin-binding site. It is instructive to view these data in light of protein-protein interaction and X-ray crystallographic analyses of the VHL-elongin C-elongin B-Cul2 complex. Elongin $\mathrm{C}$ appears to bind directly to the hCul1 homolg hCul2 (Lonergan et al 1998). The crystal structure of the VHL-elongin C-elongin B subcomplex reveals that elongin $\mathrm{C}$ also binds directly to VHL (Stebbins et al 1999). Comparison of $\mathrm{F}$ box sequences with the elongin C-binding domain of VHL reveals a similar pattern of hydrophobic residues, suggesting that $\mathrm{F}$ boxes may bind Skp1 similarly to how VHL contacts elongin C. However, residues in Skp1 analogous to those in elongin $\mathrm{C}$ that make key contacts with VHL map downstream of a Skp2-binding domain ( $\mathrm{Ng}$ et al 1998).

Sequence analysis of $s k p 1^{\text {ts }}$ alleles revealed that $s k p 1-11$ (G160E and R167K) skp1-12 (L8G), skp1-3 (I172N), and skp1-4 (L146S) carry the indicated substitutions (Bai et al 1996, Connelly \& Hieter 1996). Since all of Skp1's partners and Skp1 itself appear to be destabilized in $s k p 1-12$ cells, this allele may in part perturb the folding or stability of the mutant protein (Patton et al 1998). Interestingly, the skp1-11 and skp1-12 alleles have differential effects on proteolysis. Whereas the $\mathrm{SCF}^{\mathrm{Cdc} 4}$ substrate Sic1 is stable in skp1-11 cells, the SCF ${ }^{\mathrm{Grr} 1}$ substrates Cln2 and Gic2 are unstable in skp1-11 but stable in skp 1-12 cells (Bai et al 1996, Jacquenoud et al 1998). Although the $\mathrm{N}$-terminal domain of Skp1 probably contains a major $\mathrm{F}$ box-binding determinant ( $\mathrm{Ng}$ et al 1998, Stebbins et al 1999), these observations suggest that sequences downstream of this element stabilize association of ySkp1 with different $\mathrm{F}$ box proteins. 
Because ySkp1 can link Cdc4 to Cdc53, it has been suggested that it serves primarily to link the cullin and F box subunits of SCF. Two observations suggest that this view may be too simple. First, the F box protein Grr1 assembles with Cdc53 in insect cells in the absence of ySkp1 (although it is difficult to rule out a contribution by insect Skp1) (Skowyra et al 1997). Second, hCul1 assembles with the F box protein Skp2 in the absence of any other eukaryotic proteins (Lyapina et al 1998), and a mutation in Skp2 that blocks binding of both human cyclin A and hSkp1 has no effect on binding to hCul1 in human cells (Lisztwan et al 1998). Perhaps a more subtle function of Skp1 is to position the F box and cullin subunits so that they are optimally placed to mediate transfer of ubiquitin from E2 enzyme to substrate.

\section{Architecture of Cdc53}

Cdc53 is subdivided into three domains: an N-terminal domain that binds ySkp1, an internal domain that recruits yCdc34 and Hrt1, and a short C-terminal domain of unknown function. Cdc53 lacking amino acids 448-748 [i.e. Cdc53( $\Delta 448-$ 748)] binds to both ySkp1 and F box proteins in coimmunoprecipitation assays,

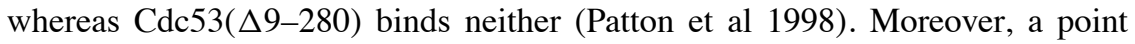
mutation in the conserved N-terminal domain residue Y133 disrupts association between Cdc53 and ySkp1 (M Tyers, personal communication). Finally, the first 219 amino acids of hCul1 bind both hSkp1 and hSkp2 in two-hybrid and GST pull-down assays (Michel \& Xiong 1998). Taken together, these data indicate that the first 219 amino acids of hCul1/Cdc53 comprise a Skp1-binding domain. The bound Skp1 in turn facilitates association with $\mathrm{F}$ box proteins. Because bacterially expressed hCul1 and hSkp1 interact, binding is likely to be direct (Lyapina et al 1998). Interestingly, the $\mathrm{N}$-terminal domain shows the lowest conservation among cullins of the three domains discussed here, and hCul2-hCul5 do not bind hSkp1 in a two-hybrid assay (Michel \& Xiong 1998). This observation is considered in more detail in the section Diversification of SCF Function.

Whereas N-terminal deletion mutants of Cdc53 and hCul1 no longer bind Skp1, they do bind to yCdc34 and Roc1/Rbx1, respectively (Ohta et al 1999, Patton et al 1998). Thus the region C-terminal to the Skp1-binding domain constitutes a Cdc34/RING-H2 subunit-recruiting domain. The $c d c 53-1$ mutation (R488C) lies within this segment and specifically disrupts Cdc53-yCdc34 interaction (Patton et al 1998). This region of Cdc53 is conserved with the APC/C subunit Apc2, and is called the cullin homology $(\mathrm{CH})$ domain (H Yu et al 1998, Zachariae et al 1998). The $\mathrm{CH}$ domain likely represents a conserved module for linking a ubiquitin-conjugating enzyme to a ubiquitin ligase. Given that (a) Hrt1 binds directly to yCdc34 (Seol et al 1999), (b) Hrt1/Roc1/Rbx1 appears to bind directly to Cdc53/hCul1 (Ohta et al 1999, Seol et al 1999, Tan et al 1999), (c) Hrt1 stabilizes the association of yCdc34 with Cdc53 (Skowyra et al 1999), and (d) yCdc34 and Roc1/Rbx 1 bind overlapping regions of Cdc53/hCul1 (Ohta et al 1999, Patton 
et al 1998), it seems likely that Hrt1 helps tether yCdc34 to the $\mathrm{CH}$ domain by binding directly to both proteins.

The most confounding element of Cdc53 is its extreme $\mathrm{C}$ terminus. Whereas this is the most highly conserved region of cullin proteins and is required for attachment of Rub1 (Lammer et al 1998, Patton et al 1998, Wada et al 1999), a mutant that lacks this segment (e.g. amino acids 757-814) can complement $c d c 53 \Delta$ (Lammer et al 1998, Patton et al 1998) and actively mediates Sic1 ubiquitination in vitro (Feldman et al 1997).

\section{Architecture of Hrt1}

Hrt1 is a 121-amino acid protein that can be divided into two domains: a 54-amino acid N-terminal domain and a 67-amino acid C-terminal domain that contains the RING-H2 finger. Both domains are conserved among eukaryotic Hrt1 homologs. Despite being such a small protein, Hrt1 binds Cdc53, yCdc34, and the F box proteins Grr1 and Cdc4 (Kamura et al 1999, Seol et al 1999, Skowyra et al 1999). Binding of Hrt1 to yCdc34 is direct since it can be reconstituted with proteins isolated from E. coli (Seol et al 1999). Binding of Hrt1/Roc1/Rbx 1 to cullins and $\mathrm{F}$ box proteins is also likely to be direct. Roc1/Rbx1 and the related hRoc 2 bind hCul1-hCul5 in both two-hybrid and co-immunoprecipitation assays (Ohta et al 1999). Likewise, hApc11 binds the cullin-related hApc2. Thus all known proteins that contain cullin homology domains can assemble with RING-H2 proteins. $\mathrm{CH}$ and RING-H2 proteins may comprise a conserved heterodimeric core that lies at the heart of a diverse array of ubiquitin ligase complexes (see section titled $F$ Boxes, SOCS Boxes, and Others).

Mutation of conserved cysteine and histidine residues in the RING-H2 domain abrogates the ability of Roc1/Rbx 1 to complement yeast $h r t 1 \Delta$ mutants and sustain ubiquitin ligase activity in vitro (Kamura et al 1999, Ohta et al 1999). The RING-H2 mutants still bind $\mathrm{Cdc} 53 / \mathrm{hCul1}$, suggesting that their defect arises from impaired interaction with Cdc34. An intriguing feature of the RING-H2 domain is that it contains three cysteines (at positions 66, 69, and 81 in Hrt1) that are not part of the canonical RING motif but are nevertheless conserved in all Hrt1/Roc1/Rbx 1 and Apc11 homologs. However, Roc1/Rbx1 lacking the first two cysteines can still complement $h r t 1 \Delta$ cells, and $h r t 1 \mathrm{~K} 72 \mathrm{R}$ C81R double mutants are viable (Kamura et al 1999, Skowyra et al 1999). Thus these additional cysteines are not absolutely essential for activity.

\section{Architecture of F Box Proteins}

$\mathrm{F}$ box proteins come in many different forms. All $\mathrm{F}$ box proteins share the $\sim 45$ amino acid $\mathrm{F}$ box domain, but are otherwise very dissimilar. For example, Cdc4 and $\mathrm{h} \beta$-TrCP/E3RS contain seven WD-40 repeats in addition to the $\mathrm{F}$ box domain, whereas Grr1 and Skp2 each contain multiple leucine-rich repeats. Other repeat domains are found in $\mathrm{F}$ box proteins, and some $\mathrm{F}$ box proteins are composed of only unique sequences outside of the F box (Patton et al 1998a). 
Numerous mutagenesis studies have confirmed that an intact $\mathrm{F}$ box is required for association with Skp1. The most highly conserved residue in the F box is a proline near the $\mathrm{N}$-terminal boundary that is typically preceded by a leucine. The Leu-Pro dipeptide is required for association of Cdc4 (Bai et al 1996) and Ctf13 (Kaplan et al 1997) with ySkp1. However, the conserved proline is not required for interaction of Skp2 with hSkp1 (Yam et al 1999). The conserved Leu-Pro dipeptide is absent from several $\mathrm{F}$ box family members identified in database searches (Patton et al 1998a; K Hofmann, personal communication). It remains unclear whether these proteins bind Skp1. A more detailed understanding of the F box-Skp1 interface awaits a systematic mutagenesis of the F box and structural studies.

Although the $\mathrm{F}$ box is required to bind Skp1, it may not be sufficient. For example, the minimal $\mathrm{F}$ box of Grr1 does not bind ySkp1 in a two-hybrid assay (Li \& Johnston 1997), and an N-terminal fragment of Cdc4 that contains an F box but lacks the C-terminal WD-40 repeat domain coimmunoprecipitates poorly with ySkp1 (Zhou \& Howley 1998). Lastly, mutation of two residues near the $\mathrm{C}$ terminus of Skp2 (far downstream of the F box) disrupts binding of both human cyclin A and hSkp1 (Lisztwan et al 1998). Thus stable interaction between $\mathrm{F}$ box proteins and Skp1 may typically require sequences lying outside the $\mathrm{F}$ box.

\section{Architecture of F Box Proteins: Cdc4}

Domain analyses have been performed on four $\mathrm{F}$ box proteins: $\mathrm{Cdc} 4, \mathrm{~h} \beta-\operatorname{TrCP} /$ E3RS, Grr1, and Skp2. The results obtained for Cdc4 are discussed here. Cdc4 can be divided into four domains: a unique $\mathrm{N}$-terminal domain, the $\mathrm{F}$ box, a C-terminal domain that contains seven WD40 repeats, and an $\sim 50$ amino acid segment between the F box and WD-40 domains that appears to control turnover of Cdc4 (Matthias et al 1999). An intact WD-40 domain is required for Cdc4 to bind Sic1 but not ySkp1 (Skowyra et al 1997), and the WD-40 region by itself is sufficient to bind phosphorylated Sic1 (C Correll, personal communication). Whereas binding of phosphorylated Sic1 substrate to full-length Cdc4 is strongly stimulated by ySkp1 (Feldman et al 1997, Skowyra et al 1997), Skp1 has no effect on the binding of phospho-Sic1 to the isolated WD-40 domain (C Correll, personal communication). Taken together, these observations suggest that the unoccupied F box antagonizes the substrate-binding activity of the WD-40 domain. Such an autoinhibitory mechanism would insure that free $\mathrm{F}$ box subunits do not compete with intact SCF complexes for access to substrates.

The WD-40 domain of the $\mathrm{F}$ box protein $\mathrm{h} \beta$ - TrCP/E3RS has also been shown to recruit substrates for ubiquitination (Margottin et al 1998, Yaron et al 1998). This activity has been exploited to construct dominant-negative mutations that selectively interfere with the destruction of $\mathrm{h} \beta-\operatorname{TrCP} / \mathrm{E} 3 \mathrm{RS}$ targets. The idea is that a WD-40 domain that lacks an associated $\mathrm{F}$ box competes with the intact protein for binding substrate, but does not deliver bound substrates to SCF due to its inability to bind Skp1. Although this tactic has been applied successfully to stabilize CD4 
(Margottin et al 1998), I $\kappa$ B (Yaron et al 1998, Kroll et al 1999, Hatakeyama et al 1999, Fuchs et al 1999), and $\beta$-catenin (Marikawa \& Elinson 1998, Latres et al 1999, Fuchs et al 1999, Hart et al 1999), overexpression of Cdc4's WD-40 domain appears to have no effect on destruction of Sic1 (Zhou \& Howley 1998). Nevertheless, deletion of the F box from SCF substrate receptors is an attractive strategy for producing dominant-negative proteins that interfere with the degradation of only those substrates that utilize the mutated $\mathrm{F}$ box protein as a receptor. In contrast, a dominant-negative strategy aimed at the other subunits of SCF is likely to disable the entire spectrum of SCF complexes present in the cell.

$\mathrm{Cdc} 4$ expressed in insect cells is multimeric and is able to direct assembly of a multimeric SCF complex (C Correll, personal communication). Likewise, the Schizosaccharomyces pombe Cdc4 homologs Pop1 and Pop2/Sud1 form heteroand homo-oligomers (Kominami et al 1998, Wolf et al 1999). Although it remains unclear whether Pop1/Pop2 heterodimers assemble into multimeric SCF complexes, deletion analysis and characterization of Pop1/Pop2 chimeras suggest that interaction of these proteins is important for their genetic function (Wolf et al 1999). It remains unclear if higher-order assembly of SCF is crucial for its function and if all $\mathrm{F}$ box-containing proteins oligomerize. In contrast to Cdc4, Pop1, and Pop2, the Cdc53 and ySkp1 subunits do not form stable homo-oligomers (C Correll, personal communication).

\section{Architecture of yCdc34}

Unlike most $\mathrm{E} 2$ enzymes, yCdc34 contains an extensive C-terminal tail in addition to the core enzymatic domain. Domain-swapping experiments demonstrated that the unique tail domain is able to confer yCdc34's cell cycle regulatory function upon the heterologous E2 enzyme Rad6 (Kolman et al 1992, Silver et al 1992). yCdc34( $\Delta 210-295)$, which contains the catalytic domain and the first 39 residues of the tail domain, complements $c d c 34 \Delta$ (Mathias et al 1998, Ptak et al 1994). Although yCdc34 does not behave as a stable multimer in hydrodynamic analyses, it can readily be cross-linked into dimers and higher-order oligomers, and this interaction requires amino acids 185-209 (Ptak et al 1994). Moreover, coexpressed catalytic and tail domain fragments suppress $c d c 34-1^{t s}$ mutants (Silver et al 1992). Recently, Mathias et al (1998) showed that yCdc34(171-209) recruits Cdc53 and Cdc4. Taken together, these data indicate that the proximal portion of the tail domain contacts the catalytic domain and mediates both multimerization of yCdc34 and its assembly with SCF.

\section{POST-TRANSLATIONAL CONTROL OF SCF PATHWAY COMPONENTS}

Since SCF activity can be reconstituted in vitro with Cdc4, ySkp1, Hrt1, and yCdc34 proteins produced in E. coli (Feldman et al 1997, Seol et al 1999), eukaryote-specific post-translational modifications cannot be essential for the 
activity of these subunits. However, post-translational modifications of SCF subunits may regulate SCF activity in vivo, modulate the shuttling of SCF complexes or components to different parts of the cell, or influence the remodeling of SCF complexes in response to cellular or environmental signals. The following sections describe what is known about the modification state, post-translational regulation, and localization of SCF subunits.

\section{Post-Translational Regulation of Skp1}

Skp1 purified from Dictyostelium discoideum cells contains a linear pentasaccharide chain attached to a hydroxylated proline at position 143 (Teng-umnuay et al 1998). Although this residue is conserved in budding yeast, Arabidopsis, and C. elegans Skp1, it is not present in the human or mouse proteins. Skp1 is also phosphorylated upon expression in insect cells, but the significance of this modification has not been evaluated (Kaplan et al 1997). ySkp1 is stable (Zhou \& Howley 1998), and the levels of hSkp1 (Lisztwan et al 1998) and ySkp1 (JH Seol, personal communication) do not vary during the cell cycle. Interestingly, both Skp1 and Cul1 colocalize to the centrosome in animal cells (Freed et al 1999, Gstaiger et al 1999). It has been well established that proteolysis triggers the separation of sister chromatids at the beginning of anaphase. SCF-dependent degradation may play an analogous role in centrosome duplication, since the proteasome inhibitor lactacystin and antibodies against hSkp1 and hCul1 block separation of centrioles in vitro (Freed et al 1999).

\section{Post-Translational Regulation of Cdc53/Cullin}

The best-characterized post-translational modification of SCF is the attachment of the ubiquitin-related protein Rub1 (known as Nedd8 in humans) to Cdc53 (Lammer et al 1998, Liakopoulos et al 1998), rabbit Cul-4A (Osaka et al 1998), and hCul2 (Wada et al 1999). Strikingly, Cdc53 and Cul-4A appear to be the most prominent attachment sites for Rub1/Nedd8 in budding yeast cells and rabbit reticulocyte lysates, respectively. Attachment of Rub1/Nedd8 to proteins (i.e. rubinylation) mimics attachment of ubiquitin, and requires E1- and E2-like activities. The Rub1-activating enzyme is divided into two subunits that are homologous to the $\mathrm{N}$ - and $\mathrm{C}$-terminal halves of $\mathrm{E} 1$. The $\mathrm{N}$-terminal subunit is known as Ula1/Enr2 in budding yeast and APP-BP1 in human, whereas the C-terminal subunit is known as Uba3 in both organisms (Liakopoulos et al 1998, Osaka et al 1998, Gong \& Yeh 1999). Genes encoding these subunits have been identified in a broad range of eukaryotes (Lammer et al 1998). A Rub1/Nedd8-conjugating enzyme, Ubc12, has also been reported (Liakopoulos et al 1998, Osaka et al 1998, Gong \& Yeh 1999). Human and yeast Ubc12 are homologous and are clearly related to ubiquitinconjugating enzymes. It remains unclear whether rubinylation involves an E3-like activity. Accumulation of Rub1-Cdc53 conjugates in vivo is diminished in $s k p I^{t s}$ mutants (Lammer et al 1998), but this may be due either to stabilization of Cdc53 by ySkp1 (Patton et al 1998) or to an E3-like function of ySkp1 in the rubinylation pathway. 
Yeast cells that lack the genes encoding Rub1, Ula1/Enr2, or yUbc12 are viable and display no obvious phenotype (Lammer et al 1998, Liakopoulos et al 1998). Thus decoration of Cdc53 with Rub1 is not crucial for SCF activity. However, mutations that disable the rubinylation pathway render cells more sensitive to the effects of mutations in SCF subunits (Lammer et al 1998). Thus Rub1 appears to enhance SCF activity, at least under conditions in which SCF is crippled. Rubinylation of Cdc53 in turn may be governed by the assembly or activity of the SCF complex because the $c d c 53-1$ mutation increases the fraction of Cdc53 that is conjugated with Rub1, whereas $s k p 1^{t s}$ mutations have the opposite effect (Lammer et al 1998). The residues in hCul1 and hCul2 that are linked to Rub1 have been mapped to the lysine in the conserved VRIMK sequence (K686) (Wada et al 1999; S Schwartz, personal communication). Deletion of sequences downstream of the VRIMK element eliminates rubinylation of $\mathrm{Cdc53}$, suggesting that other C-terminal domain sequences are required for proper modification.

The ubiquitin-like modifier SUMO-1 is thought to influence localization of the proteins to which it is attached. Centrosomal fractions have significant amounts of modified Cul1 but are devoid of the unmodified protein (Freed et al 1999), suggesting that rubinylation may likewise influence subcellular localization of SCF complexes (see also Post-Translational Regulation of Skp1).

Other than rubinylation, the cullins have not been reported to receive other posttranslational modifications. Moreover, Cdc53 is stable (Zhou \& Howley 1998), and the levels of hCul1 (Lisztwan et al 1998) and Cdc53 (JH Seol, personal communication) do not vary during the cell cycle.

\section{Post-Translational Regulation of Hrt1}

Covalent modification, stability, and subcellular localization of Hrt1 proteins have yet to be investigated. Hrt1 expressed in bacteria binds SCF components and stimulates $\mathrm{SCF}^{\mathrm{Cdc} 4}$ ubiquitin ligase, indicating that no post-translational modifications specific to eukaryotic cells are absolutely required for Hrtl activity (Seol et al 1999).

\section{Post-Translational Regulation of F Box Proteins}

Protein degradation may play a key role in sculpting the repertoire of SCF complexes in vivo. The F box proteins Cdc4, Grr1, and Met30 are unstable, and the turnover of Cdc4 and Grr1 has been investigated in detail (Galan \& Peter 1999, Zhou \& Howley 1998, Mathias et al 1999). Cdc4 and Grr1 are unstable throughout the cell cycle, and both proteins are stabilized in proteasome, $c d c 53^{t s}, c d c 34^{t s}$, and skp ${ }^{t s}$ mutants. Both Cdc4 and Grr1 are ubiquitinated and are stabilized by expression of mutant ubiquitin. Interestingly, an intact $\mathrm{F}$ box is required for turnover of both Cdc4 and Grr1.

Based on these data, Zhou \& Howley (1998) proposed that F box receptors and their bound substrates are degraded as a unit to ensure a continuous release of free 
ySkp1/Cdc53/Hrt1 subcomplexes able to assemble with newly synthesized $\mathrm{F}$ box receptor subunits. Their hypothesis predicts that the rate of degradation of an $\mathrm{F}$ box protein should be directly proportional to the concentration of its substrates. This prediction has not been tested. I suggest an alternative model that predicts the rate of degradation of $\mathrm{F}$ box proteins to be inversely proportional to the concentration of their substrates. According to this view, binding of substrate shields the F box subunit from autoubiquitination, and overexpression of substrate is thus predicted to stabilize the corresponding $\mathrm{F}$ box receptor. This substrate shield model is attractive in that it would ensure a direct correlation between the concentration of a given $\mathrm{F}$ box protein and the concentration of its targets. Thus there would be no need for the cell to regulate with a high degree of accuracy the synthesis of every $\mathrm{F}$ box protein. If a given $\mathrm{F}$ box protein were synthesized in excess, its levels would be quickly pared down to match substrate demand.

Aside from the yeast $\mathrm{F}$ box proteins discussed above, Skp2 is also likely to be unstable, since its levels fluctuate during the cell cycle, reaching a peak during $\mathrm{S}$ phase (Lisztwan et al 1998).

\section{Post-Translational Regulation of Cdc34}

yCdc34 is phosphorylated on serine residues in vivo (Goebl et al 1994), but it remains unclear if this modification regulates its activity. yCdc34 isolated from $E$. coli supports SCF-dependent ubiquitination in a purified system (Feldman et al 1997), indicating that phosphorylation is not required for its catalytic activity or interaction with SCF. yCdc34 ubiquitinates itself both in vitro and in vivo (Banerjee et al 1993, Goebl et al 1994). Autoubiquitination of yCdc34 requires a cluster of four lysine residues in the extreme $C$ terminus (Banerjee et al 1993), deletion of which has no apparent effect on yCdc34 function (Goebl et al 1994). Immunoblot analyses reveal that yCdc34 levels are equivalent in cells arrested in G1, S, or $\mathrm{M}$ phase (Mathias et al 1998) and remain constant during progression through a synchronous cell cycle (Galan \& Peter 1999; JH Seol, personal communication). In short, there is no evidence that yCdc34 activity is regulated by either post-translational modification or degradation.

\section{SUBSTRATES OF THE SCF PATHWAY}

Many proteins have been implicated as substrates of SCF by a variety of criteria, including stabilization or accumulation in SCF pathway mutants, stabilization upon expression of dominant-negative F box proteins, and reconstitution of SCFdependent ubiquitination with either purified proteins or in a crude system. These substrates represent a broad spectrum of proteins that participate in a variety of cellular functions, including regulation of CDK activity, activation of transcription, signal transduction, assembly of kinetochores, and DNA replication. Rather than discuss each substrate in detail, those known to date are described briefly in Table 2. 


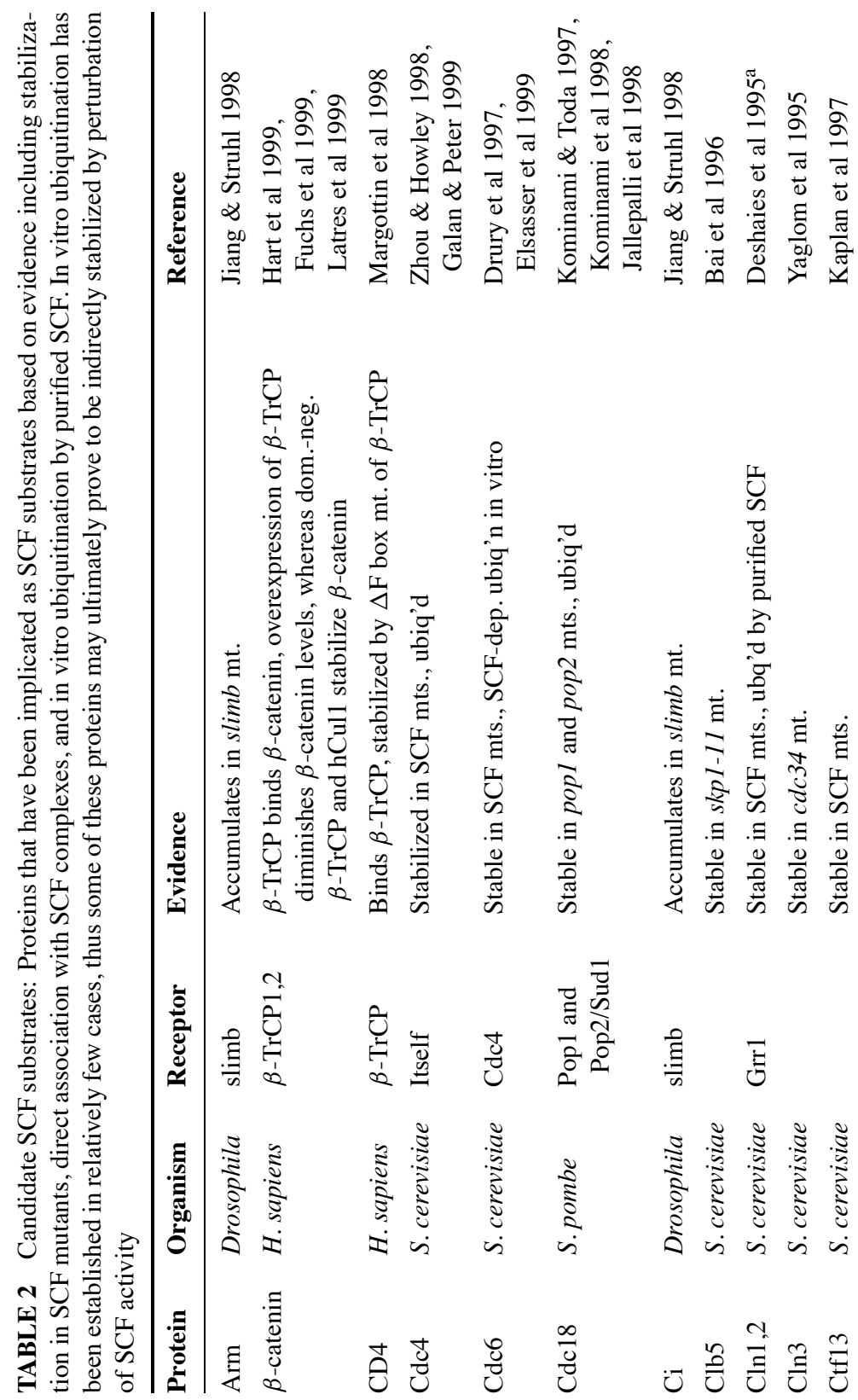




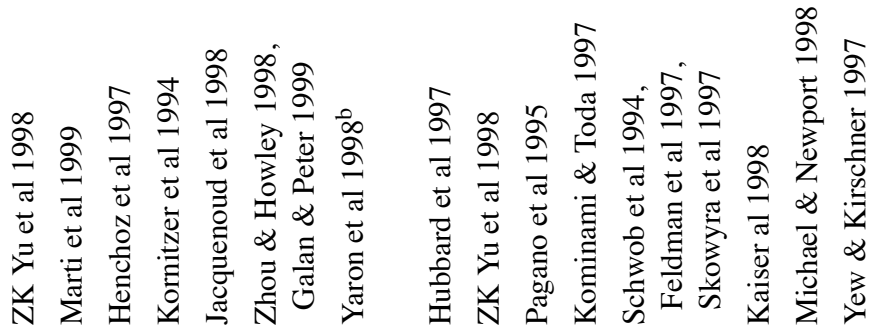

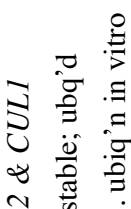

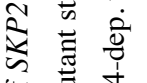

ह

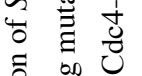

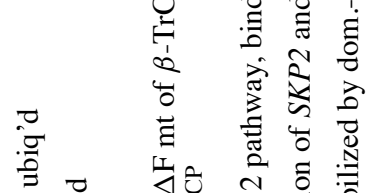

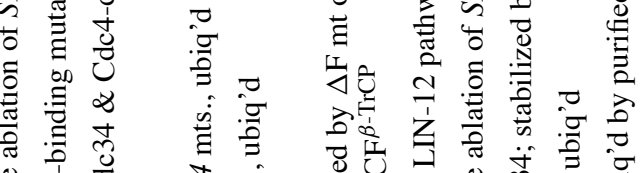

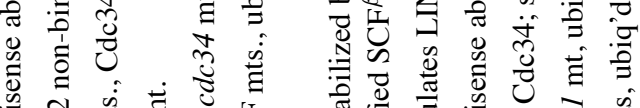

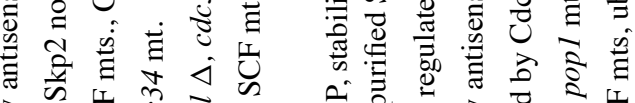

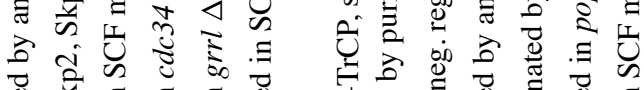

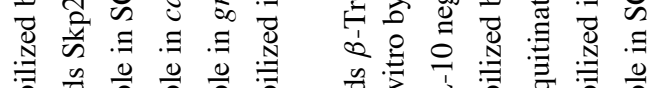

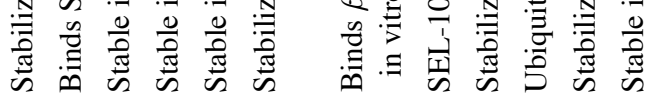

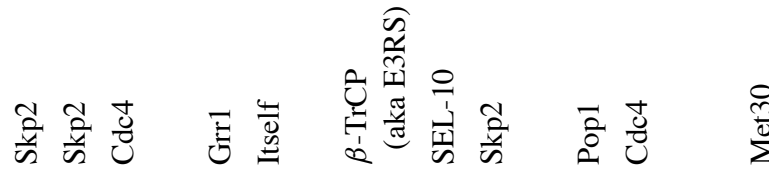

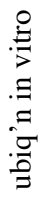

过

帘

를

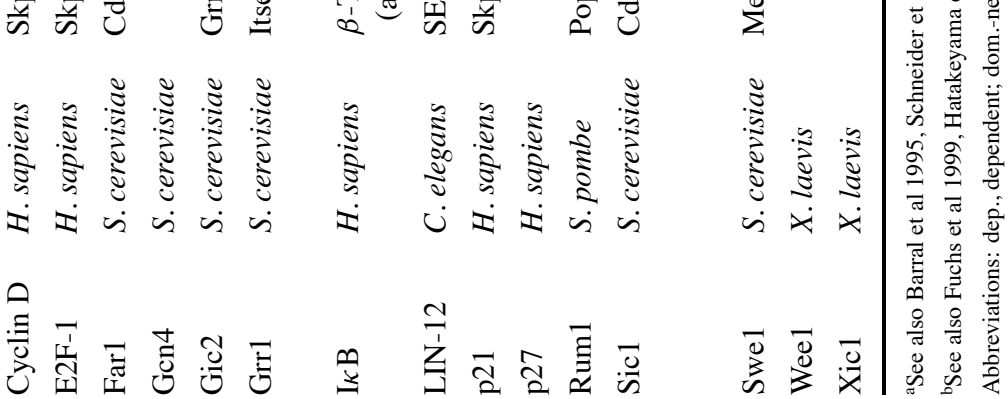




\section{MECHANISM OF ACTION OF SCF}

\section{How Does Substrate Bind SCF?}

In all the examples studied thus far in detail (ubiquitination of $C \ln 1$ and 2 by $\mathrm{SCF}^{\mathrm{Grrl}}$, $\mathrm{Sic} 1$ by $\mathrm{SCF}^{\mathrm{Cdc} 4}$, and $\mathrm{I} \kappa \mathrm{B}$ plus $\beta$-catenin by $\mathrm{SCF}^{\beta-\mathrm{TrCP} / \mathrm{E} 3 \mathrm{RS}}$; consult Table 2 for references), the target must be phosphorylated before it can bind and serve as a substrate for SCF. This common requirement for phosphorylation is remarkable given that the substrate-binding domains of $\mathrm{Cdc} 4$ and $\beta$-TrCP/E3RS are constructed of WD-40 repeats, whereas that of Grr1 is constructed of completely dissimilar leucine-rich repeats (Kishi et al 1998). All known substrates of SCF Cdc4 -Sic1 (Feldman et al 1997, Skowyra et al 1997, Verma et al 1997), Gcn4 (Y Chi, personal communication), Far1 (Henchoz et al 1997), and Cdc6 (Elsasser et al 1999) must be phosphorylated before they can be ubiquitinated. How does phosphate drive the interaction of diverse substrates with SCF? Phosphopeptides (but not their unmodified counterparts) derived from $\mathrm{I} \kappa \mathrm{B}$ are able to compete with full-length $\mathrm{I} \kappa \mathrm{B}$ for binding to $\beta$-TrCP/E3RS (Yaron et al 1998, Winston et al 1999). These data suggest that the WD- 40 domain of $\beta$-TrCP/E3RS constitutes a phospho-serine recognition module. It remains an open question whether all SCF complexes will prove to be specific for phosphorylated substrates.

Several $\mathrm{F}$ box proteins contain WD-40 repeats. The properties of this domain may allow SCF complexes to bind a diverse spectrum of substrates. The WD-40 repeats of $\mathrm{Cdc} 4$ are predicted to fold into a $\beta$-propeller based on the crystal structure of the WD-40 repeat domain of the $\mathrm{G} \beta$ subunit of heterotrimeric $\mathrm{G}$ proteins (Lambright et al 1996, Sondek et al 1996, Wall et al 1995). The face of the $\beta$ propeller in $\mathrm{G} \beta$ presents a broad platform for protein-protein interaction. Different signaling proteins interact with the face of $\mathrm{G} \beta$ 's propeller domain by forming stabilizing contacts with different residues on the propeller's face, such that each effector makes a slightly different footprint on the platform (Ford et al 1998). This plasticity may explain why the known substrates of Cdc4 do not show any apparent sequence homology with each other in their destabilizing domains. However, since all $\mathrm{SCF}^{\mathrm{Cdc} 4}$ substrates must be phosphorylated before they can bind, Cdc4's $\beta$-propeller domain likely contains a phosphate-binding pocket that aligns the substrate on the propeller's surface.

The requirement for substrate phosphorylation creates an opportunity to differentially regulate the stability of distinct $\mathrm{SCF}^{\mathrm{Cdc} 4}$ substrates. Whereas Sic1 and Far1 are activated to bind Cdc4 following their phosphorylation by G1 cyclin/Cdc28 (Feldman et al 1997, Henchoz et al 1997, Skowyra et al 1997), Cdc6 is targeted to SCF upon its phosphorylation by S cyclin/Cdc28 (Elsasser et al 1999). The Cdc42 GTPase effector Gic2 (Jaquenoud et al 1998) and the transcriptional activator Gcn4 (Y Chi, personal communication) are phosphorylated and targeted for SCF-dependent ubiquitination by protein kinases other than Cdc28. By linking the SCF-dependent ubiquitination of substrates to the action of distinct kinases, it is possible to achieve substrate-specific degradation in response to diverse 
environmental or intracellular cues. For example, although $\mathrm{SCF}^{\mathrm{Cdc} 4}$ is active in preSTART G1 extracts, Sic 1 is stable until $\mathrm{Cln} / \mathrm{Cdc} 28$ protein kinase is activated at START (Schneider et al 1996, Verma et al 1997a). Besides allowing for temporal regulation, the requirement for substrate phosphorylation can be exploited in other ways. A Cln2 mutant that cannot bind $\mathrm{Cdc} 28$ is not phosphorylated and consequently stabilized (Deshaies et al 1995, Lanker et al 1996), and a mutant of Gic2 that fails to bind yCdc42 is likewise not phosphorylated and is stabilized (Jaquenoud et al 1998). In both cases, the requirement for substrate phosphorylation ensures that the attention of the degradation machinery is focused on the specific subset of substrate molecules.

\section{How is Ubiquitin Transferred From Cdc34 to Substrate?}

The ubiquitin ligase best characterized to date, the HECT domain family member E6-AP, contains an essential cysteine residue that accepts ubiquitin from E2 enzyme and subsequently transfers it to a lysine residue of the substrate p53 (Scheffner et al 1995). Because HECT domain family members are the only ubiquitin ligases known to form a thioester intermediate with ubiquitin, it remains unclear whether other ubiquitin ligases operate via a similar mechanism. All cysteine residues in Cdc53 and ySkp1 are dispensable for function (Patton et al 1998), as are three conserved cysteines in Hrt1/Roc1/Rbx1 that are not part of the RING-H2 consensus (Kamura et al 1999, Skowyra et al 1999). Thus if SCF forms an obligate covalent intermediate with ubiquitin during its transfer from yCdc34 to substrate, the catalytic site must either be present on a prosthetic group (similar to the reactive thiol group in the acyl carrier protein of the fatty acid synthase complex), or there must be an essential ubiquitin-accepting residue of SCF that remains to be identified.

Recent work suggests that the cullin/RING-H2 subunits serve as the core ubiquitin ligase module of the SCF complex. This conclusion stems from the observation that cullin/RING-H2 heterodimers appear to be sufficient to activate assembly of either free (Ohta et al 1999, Tan et al 1999) or Cdc34-bound (Seol et al 1999, Skowyra et al 1999) multiubiquitin chains (note that it has not been rigorously excluded that the free multiubiquitin chains reported by Tan, Ohta, and colleagues are in fact not anchored to hCdc34 or hCul1).

Intriguingly, whereas enzymes that use cysteine residues for catalysis (including E1 enzyme) are sensitive to alkylating agents such as $N$-ethylmaleimide (NEM), $\mathrm{Cdc53/Hrt1}$ pretreated with NEM retains its ability to activate autoubiquitination of yCdc34 (Seol et al 1999). Moreover, polycations that lack sulfhydryls can substitute for SCF and promote yCdc34-dependent ubiquitination of Gcn4 or autoubiquitination of yCdc34. Based on these observations, Seol et al (1999) proposed that cullin and RING-H2 proteins form a ubiquitin ligase module that operates by a mechanism distinct from that of the HECT domain ligases. Cdc53/Hrt1 may trigger a conformational change in yCdc34-S-Ub that reduces the energy barrier to forming the oxyanionic intermediate that occurs in the transition state as the $\mathrm{C}$ terminus 
of ubiquitin is transferred from the catalytic cysteine of yCdc 34 to the $\varepsilon$-amino group of a substrate lysine. A conformational switch in yCdc 34 driven by specific interaction with $\mathrm{Cdc53} / \mathrm{Hrt} 1$ would minimize the possibility that yCdc34 (which is present in substantial excess in vivo compared with SCF complexes; JH Seol, personal communication) would gratuitously ubiquitinate proteins with which it inevitably collides in the densely packed cell. A logical extension of this argument is that the ubiquitination-promoting activity of Cdc53/Hrt1 may be gated within the SCF complex such that it is maximally expressed upon docking of substrate to the F box receptor subunit. Besides SCF and APC/C, a number of known or suspected ubiquitin ligases contain a RING or RING-H2 domain, including Ubr1 (Kwon et al 1998), Hrd1/Der3 (Bordallo et al 1998, Hampton et al 1996), SINA (Hu \& Fearon 1999), Rad18 (Bailly et al 1997) and Mdm2 (Honda et al 1997). It will be interesting to see whether all RING-bearing ubiquitin ligases operate by a common mechanism.

It is worth noting that SCF occasionally associates with $\mathrm{E} 2$ enzymes other than $\mathrm{Cdc} 34$. The $\beta$-TrCP/E3RS-dependent ubiquitination of $\mathrm{I} \kappa \mathrm{B}$, for example, involves a member of the hUbc5 family of E2 enzymes (Yaron et al 1998, Spencer et al 1999). In addition, the Grr1-, y Skp1-, and Cdc53-dependent regulation of glucoserepressible genes in yeast does not require yCdc34, suggesting that another E2 enzyme is involved (Li \& Johnston 1997).

\section{How Does SCF Promote the Assembly of a Multiubiquitin Chain?}

At first glance, it is difficult to envision how the assembly of a multiubiquitin chain occurs in three dimensions. If one's reference point is the SCF complex, the substrate (i.e. the end of the growing ubiquitin chain) should move farther away with each cycle of ubiquitin addition. Nevertheless, SCF/yCdc34 rapidly assembles multiubiquitin chains upon Sic1. One can envision several explanations to account for processive assembly of multiubiquitin chains. For example, SCF may trigger the assembly of an oligomer of yCdc34 that provides a template for the assembly of a multiubiquitin chain. Because a tetraubiquitin chain is thought to be capable of targeting an appended protein for degradation (Piotrowski et al 1997), induced tetramerization of yCdc 34 would be sufficient to yield degradationcompetent substrate. Pure yCdc34 has already been shown to form dimers and higher-order oligomers in vitro (Ptak et al 1994). An alternative possibility is that the growing multiubiquitin chain spools away from $\mathrm{SCF} / \mathrm{yCdc} 34$ as a loop, such that the relative positions of $\mathrm{yCdc} 34, \mathrm{SCF}$, and the growing end of the ubiquitin chain remain constant throughout the process of chain assembly. The ability to processively assemble a multiubiquitin chain is likely to be a crucial aspect of SCF activity. If chain synthesis were to occur by a purely distributive mechanism, ubiquitin isopeptidases might disassemble the multiubiquitin chains before they grew to a length sufficient to mediate high-affinity interaction of substrate with the $26 \mathrm{~S}$ proteosome. 


\section{DIVERSIFICATION OF SCF FUNCTION}

\section{The F Box Hypothesis}

Based on previous observations that the $\mathrm{F}$ box-containing proteins $\mathrm{Cdc} 4$ and $\mathrm{Grr} 1$ are involved in the degradation of Sic 1 (Schwob et al 1994) and G1 cyclins (Barral et al 1995), respectively, Bai et al (1996) proposed that $\mathrm{F}$ box-containing proteins serve to link different substrates to Skp1 and the ubiquitination machinery (Figure 3). The generality of their hypothesis has been tested for two members of the $\mathrm{F}$ box family of proteins, $\mathrm{Cdc} 4$ and $\mathrm{Grr} 1$. $\mathrm{SCF}^{\mathrm{Cdc} 4}$ binds tightly to and catalyzes ubiquitination of phosphorylated Sic1, but binds poorly to phosphorylated Cln1 (Feldman et al 1997, Skowyra et al 1997). In contrast, $\mathrm{SCF}^{\mathrm{Grr} 1}$ binds tightly to and catalyzes ubiquitination of phosphorylated $\mathrm{Cln} 1$ and $\mathrm{Cln} 2$ but fails to bind phosphorylated Sic1 (Skowyra et al 1997, 1999; Seol et al 1999). Patton et al (1998) demonstrated that the F box proteins Cdc4, Grr1, and Met30 each form SCF complexes in vivo by assembling with Cdc53 and ySkp1, but that these proteins do not cross-assemble with each other, suggesting that each SCF complex is limited to a single form of $\mathrm{F}$ box receptor (however, see Kominami et al 1998, Wolf et al 1999). Moreover, whereas $c d c 53^{t s}$ and $c d c 34^{t s}$ mutants are defective in turnover of all known SCF substrates, grrl $1 \Delta$ mutants degrade Sic1 with normal kinetics but accumulate stable $\mathrm{Cln} 2$, and $c d c 4$ mutants can degrade $\mathrm{Cln} 2$ but accumulate stable Sic1.

Given that the budding yeast genome potentially encodes $17 \mathrm{~F}$ box proteins, 17 different SCF ubiquitin ligase complexes may exist in this organism (for a comprehensive display of budding yeast $\mathrm{F}$ box proteins, see Patton et al 1998a). However, at least one $\mathrm{F}$ box protein (the $\mathrm{Ctf} 13$ subunit $\mathrm{CBF} 3$ ) assembles into a macromolecular complex distinct from SCF (Connelly \& Hieter 1996, Kaplan et al 1997, Stemmann \& Lechner 1996). It remains to be seen how many F box proteins assemble into ubiquitin ligase complexes. Nevertheless, even a subset of the known $\mathrm{F}$ box proteins might yield far more than 17 distinct SCF complexes, since there are two additional Cdc53-like proteins encoded in the budding yeast genome, and at least some $\mathrm{F}$ box proteins can form heterodimers with each other (Kominami et al 1998, Wolf et al 1999).

\section{F Boxes, SOCS Boxes, and Others}

Recent work suggests that SCF may be a paradigm for a family of modular cullinbased ubiquitin ligases. Whereas Cdc53 and hCul1 bind tightly to Skp1, the hCul2, hCul3, mouse Cul4A, and hCul5 proteins do not detectably bind hSkp1 (Michel \& Xiong 1998). In contrast, hCul2 binds elongin C, which shares homology with the N-terminal region of Skp1 (Lonergan et al 1998). Elongin C in turn binds directly to both the ubiquitin-related protein elongin B (Takagi et al 1996) and the VHL tumor suppressor protein (Takagi et al 1997). VHL shares with a number of other proteins part of a sequence referred to as the suppressor of cytokine signaling 

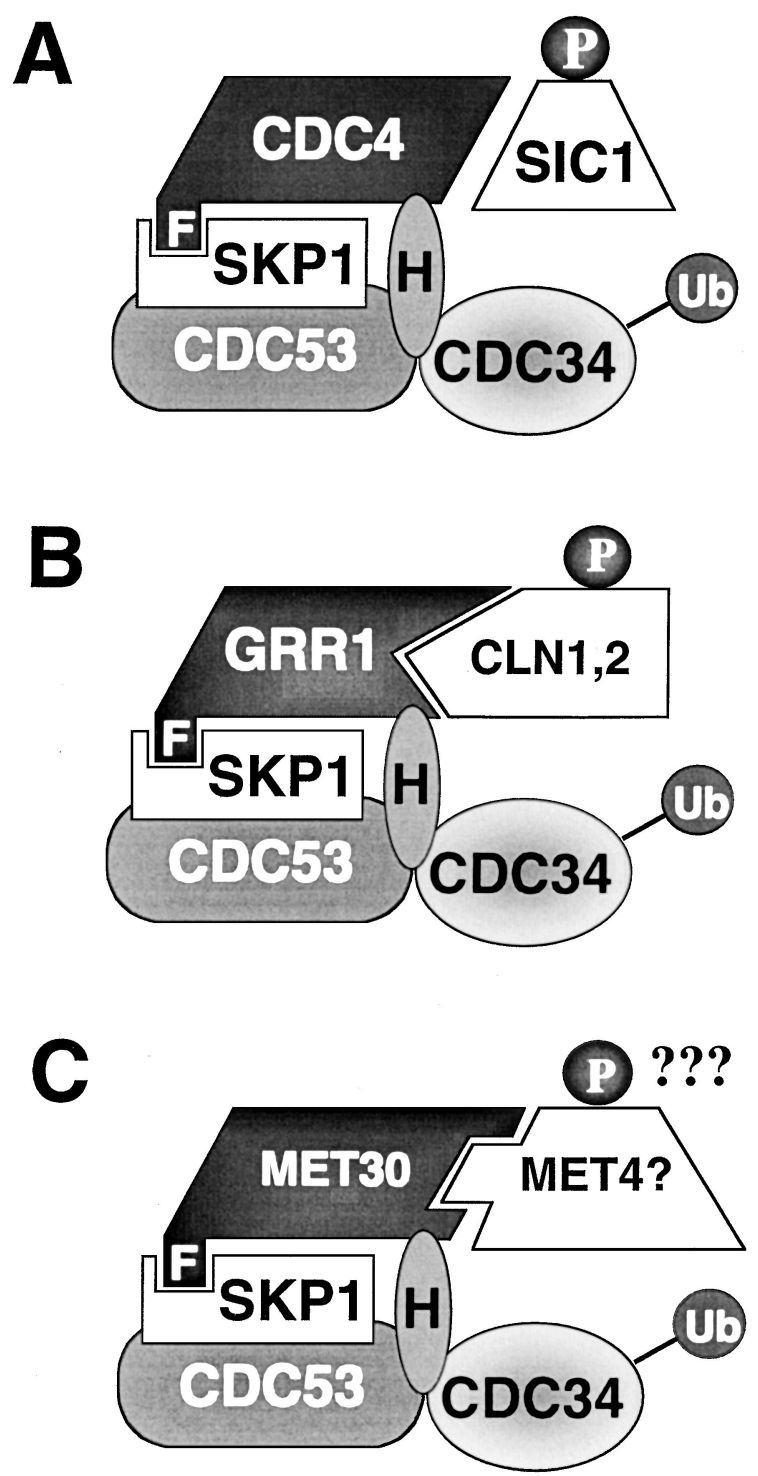

Figure 3 The F box hypothesis. ySkp1/Cdc53/Hrt1 can interact with any one of a number of different proteins that contain F boxes to yield distinct SCF complexes with different substrate specificities. As shown, $\mathrm{SCF}^{\mathrm{Cdc} 4}$ targets phospho-Sic1 for ubiquitination $(A)$, whereas $\mathrm{SCF}^{\mathrm{Grr} 1}$ targets phospho-Cln1 and phospho-Cln2 $(B)$. Genetic data suggest that Met4 may be a target of $\operatorname{SCF}^{M e t 30}(C)$, but this has not yet been shown. It is also not known whether $\mathrm{SCF}^{\mathrm{Met} 30}$ is specific for phosphoprotein substrates. H, Hrt1; F, F box. 
(SOCS) box, which was originally identified in proteins that negatively regulate cytokine-inducible signaling through the Jak/STAT pathway. SOCS box sequences from VHL, SOCS-1 and SOCS-3 are necessary and sufficient to mediate binding to elongin C (Kamura et al 1998, Kibel et al 1995, Zhang et al 1999). Taken together, these observations suggest that hCul2 and elongin $\mathrm{C}$ may form the core of a ubiquitin ligase complex (although this complex has not been shown to contain ubiquitin ligase activity) that also contains elongin B, Roc1/Rbx 1 (Kamura et al 1999), and any one of a number of SOCS box-containing proteins. The analogy to the SCF pathway, with its constellation of distinct $\mathrm{F}$ box receptors, is striking. Similarly, the APC/C, which contains both $\mathrm{CH}$ domain and RING-H2 subunits (Zacharine et al 1998, H Yu et al 1998), interacts with at least two distinct substratetargeting proteins (Cdc20 and Hct1/Cdh1). It will be interesting to see whether all cullins serve as core subunits of multicomponent ubiquitin ligases whose substrate specificity is diversified via a repertoire of interchangeable receptor subunits (Figure 4).

A tantalizing glimpse of how cullin/RING-H2 based ubiquitin ligases might be constructed is presented by the recently solved structure of the VHL-elongin C-elongin B (VCB) complex (Stebbins et al 1999). In the VCB complex, VHL and elongin $\mathrm{C}$ serve as analogs of the $\mathrm{F}$ box receptor and Skp1 subunits of SCF, respectively. There is no known subunit of SCF corresponding to the ubiquitin-like elongin B, except perhaps the Rub1 modification upon Cdc53. Stebbins et al (1999) raise the appealing notion that the interaction of VHL with elongin $\mathrm{C}$ mimics the interaction of $\mathrm{F}$ box proteins with Skp1. An important goal will be to map the binding sites for hCul2 (Lonergan et al 1998) and Roc1/Rbx 1 (Kamura et al 1999) upon the surface of elongin C. It seems likely that they will be oriented in the same direction as a putative substrate-docking site on VHL.

\section{CONCLUSION AND PERSPECTIVES}

Rapid progress has been made over the past few years in identifying and characterizing cullin-based ubiquitin ligases. Emerging evidence suggests that there is a broad array of distinct ubiquitin ligases based on the cullin/RING-H2 module and that these ligases participate in diverse regulatory pathways. Over the next few years, it is likely that progress will accelerate and that the list of distinct SCF complexes will expand as new $\mathrm{F}$ box proteins are identified. We may also witness a similar expansion in the number of ubiquitin ligases based on Cul2-Cul5. As the list of SCF and cullin-based ubiquitin ligase complexes grows longer, it will be complemented by two parallel tracks of research. First, specific ubiquitin ligase complexes will be linked to specific processes via gene knockout studies or by investigators who fortuitously isolate SCF components or cullins in forward genetic screens. Second, researchers studying proteins that are known to be unstable (e.g. transcription factors, signaling proteins, etc) will establish links between specific SCF complexes and the turnover of these proteins. 


\section{A. Cdc53/Cul1 ubiquitin ligase}

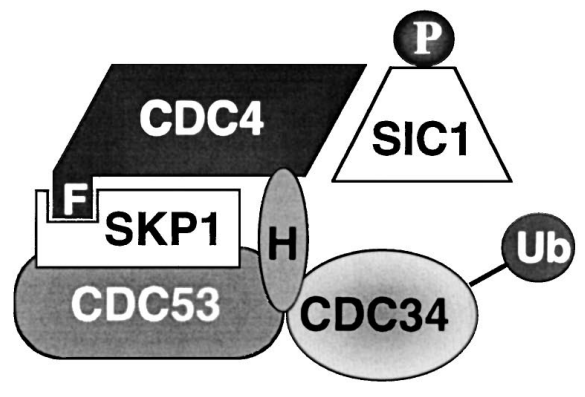

\section{B. Cul2 ubiquitin ligase}

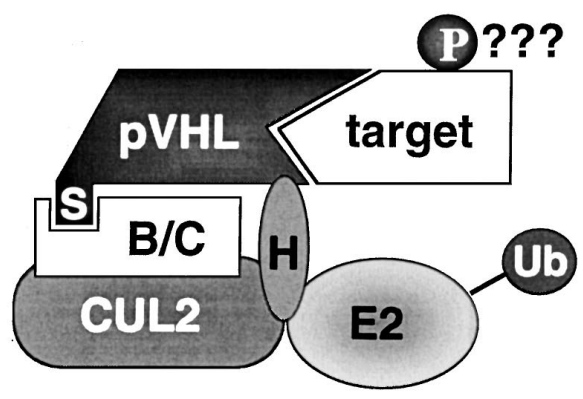

\section{Cul3-5 ubiquitin ligases?}

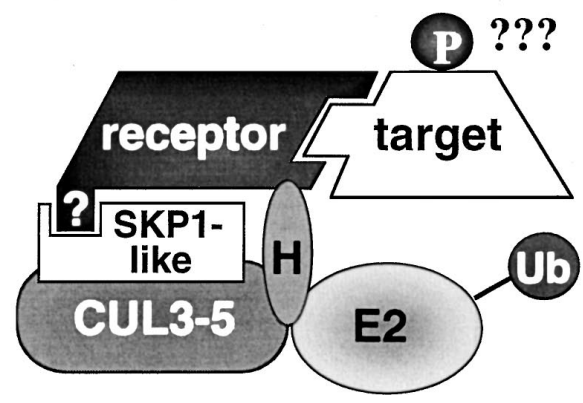

Figure 4 Do cullins define a diverse family of multisubunit ubiquitin ligases? Whereas hCul1 binds hSkp1 and assembles into SCF complexes (A), hCul2 assembles with the Skp1-like protein elongin $\mathrm{C}$, which in turn binds to a group of proteins, including the von-Hippel-Lindau (VHL) tumor supressor protein, that share a small sequence motif known as the SOCS box $(B)$. The SOCS box may function like the F box to diversify the repertoire of receptor subunits for hCul2-based ubiquitin ligase complexes. Cul3-Cul5 may also assemble into modular ubiquitin ligase complexes with an array of different substrate receptors $(C)$. It is not known whether ubiquitin ligases based on Cul2-Cul5 are specific for phosphoprotein substrates. H, Hrt1; F, F box; S, SOCS box; B/C, elongins B and C. 
Against this backdrop of anticipated progress, two lines of directed research may prove to be of particular value. First, there is currently no general method for identifying SCF substrates. Given that each SCF complex is likely to have multiple substrates, any expansion in the repertoire of known ubiquitin ligase complexes will intensify the need for efficient methods to identify substrates. Second, rapid evaluation of the function of newly discovered SCF or cullin/RING-H2 complexes in different cell lines, tissues, etc will require novel chemical or genetic strategies to inhibit ubiquitin ligase activity. Since SCF has already been linked to a number of important signaling pathways, a side benefit is that specific inhibitors may prove to have significant therapeutic benefits. Although there are no specific inhibitors available for any known ubiquitination pathway, the great success of the various proteasome inhibitors makes clear how valuable such drugs can be.

\section{ACKNOWLEDGMENTS}

I thank Richard Benarous, Zhijian Chen, Kay Hofmann, Peter Jackson, Willy Krek, Matthias Peter, Mike Tyers, and members of my laboratory for providing preprints and communicating unpublished data. I also thank Peter Jackson and Matthias Peter for critical reading of the manuscript. Work on SCF in my laboratory is supported by a grant from the National Institutes of Health, and a Young Investigator Award from the Burroughs-Wellcome Fund.

\section{Visit the Annual Reviews home page at www.AnnualReviews.org}

\section{LITERATURE CITED}

Bai C, Richman R, Elledge SJ. 1994. Human cyclin-F. EMBO J. 13:6087-98

Bai C, Sen P, Hofmann K, Ma L, Goebl M, et al. 1996. SKP1 connects cell cycle regulators to the ubiquitin proteolysis machinery through a novel motif, the F-box. Cell 86:26374

Bailly V, Lauder S, Prakash S, Prakash L. 1997. Yeast DNA repair proteins Rad6 and Rad18 form a heterodimer that has ubiquitin conjugating, DNA binding, and ATP hydrolytic activities. J. Biol. Chem. 272:23360-65

Banerjee A, Gregori L, Xu Y, Chau V. 1993. The bacterially expressed yeast $C D C 34$ gene product can undergo autoubiquitination to form a multiubiquitin chain-linked protein. J. Biol. Chem. 268:5668-75

Barral Y, Jentsch S, Mann C. 1995. G(1) cyclin turnover and nutrient-uptake are controlled by a common pathway in yeast. Genes Dev. 9:399-409

Bordallo J, Plemper RK, Finger A, Wolf DH. 1998. Der3p/Hrd1p is required for endoplasmic reticulum-associated degradation of misfolded lumenal and integral membrane proteins. Mol. Biol. Cell 9:209-22

Burnatowska-Hledin MA, Spielman WS, Smith WL, Shi P, Meyer JM, Dewitt DL. 1995. Expression cloning of an AVP-activated, calcium-mobilizing receptor from rabbit kidney medulla. Am. J. Physiol. 268:1198-210

Chen LC, Manjeshwar S, Lu Y, Moore D, Ljung BM, et al. 1998. The human homologue for the Caenorhabditis elegans cul-4 gene is amplified and overexpressed in primary breast cancers. Cancer Res. 58:3677-83

Chung CY, Reddy TB, Zhou K, Firtel RA. 1998. A novel, putative MEK kinase controls 
developmental timing and spatial patterning in Dictyostelium and is regulated by ubiquitin-mediated protein degradation. Genes Dev. 12:3564-78

Connelly C, Hieter P. 1996. Budding yeast SKPI encodes an evolutionary conserved kinetochore protein required for cell cycle progression. Cell 86:275-85

Deshaies RJ, Chau V, Kirschner M. 1995. Ubiquitination of the $\mathrm{G} 1$ cyclin $\mathrm{Cln} 2 \mathrm{p}$ by a Cdc34p-dependent pathway. EMBO J. 14: 303-12

Drury LS, Perkins G, Diffley JF. 1997. The Cdc4/34/53 pathway targets Cdc6p for proteolysis in budding yeast. EMBO J. 16:596676

Du M, Sansores-Garcia L, Zu Z, Wu KK. 1998. Cloning and expression analysis of a novel salicylate suppressible gene, Hs- $C U L-3$, a member of cullin/Cdc53 family. J. Biol. Chem. 273:24289-92

Elledge SJ, Harper JW. 1998. The role of protein stability in the cell cycle and cancer. Biochim. Biophys. Acta 1377:M61-70

Elsasser S, Chi Y, Yang P, Campbell JL. 1999. Phosphorylation controls timing of Cdc $6 \mathrm{p}$ destruction: a biochemical analysis. Mol. Biol. Cell. In press

Erhardt JA, Hynicka W, DiBenedetto A, Shen $\mathrm{N}$, Stone N, et al. 1998. A novel $\mathrm{F}$ box protein, NFB42, is highly enriched in neurons and induces growth arrest. J. Biol. Chem. 273:35222-27

Feldman R, Correll C, Kaplan K, Deshaies R. 1997. A complex of Cdc4p, Skp1p, and Cdc53p/cullin catalyzes ubiquitination of the phosphorylated CDK inhibitor Sic1p. Cell 91:221-30

Ford C, Skiba N, Bae H, Daaka Y, Reuveny E, et al. 1998. Molecular basis for interactions of $\mathrm{G}$ protein $\beta \gamma$ subunits with effectors. Science 280:1271-74

Freed E, Lacey K, Huie P, Lyapina S, Deshaies $\mathrm{R}$, et al. 1999. The Skp1 and Cul1 ubiquitin ligase components localize to the centrosome and regulate the centrosome duplication cycle. Genes Dev. In press
Fuchs S, Chen A, Xiong Y, Pan Z, Ronai Z. 1999. HOS, a human homolog of Slimb, forms an SCF complex with Skp1 and Cullin 1 and targets the phosphorylation-dependent degradation of $\mathrm{I} \kappa \mathrm{B}$ and $\beta$-catenin. Oncogene 18:2039-46

Galan J, Peter M. 1999. Ubiquitin-dependent degradation of multiple F-box proteins by an autocatalytic mechanism. Proc. Natl. Acad. Sci. USA. In press

Goebl MG, Goetsch L, Byers B. 1994. The Ubc3 (Cdc34) ubiquitin-conjugating enzyme is ubiquitinated and phosphorylated in vivo. Mol. Cell. Biol. 14:3022-29

Goebl MJ, Yochem J, Jentsch S, McGrath JP, Varshavsky A, Byers B. 1988. The yeast cell cycle gene $c d c 34$ encodes a ubiquitinconjugating enzyme. Science 241:133134

Gong L, Yeh E. 1999. Identification of the activating and conjugating enzymes of the NEDD8 conjugation pathway. J. Biol. Chem. 274:12036-42

Gstaiger M, Marti A, Krek, W. 1999. Association of human $\mathrm{SCF}^{\mathrm{SKP} 2}$ subunit $\mathrm{p} 19^{\mathrm{SKP} 1}$ with interphase centrosomes and mitotic spindle poles. J. Cell. Sci. 247:554-62

Hampton RY, Gardner RG, Rine J. 1996. Role of $26 \mathrm{~S}$ proteasome and HRD genes in the degradation of 3-hydroxy-3-methylglutarylCoA reductase, an integral endoplasmic reticulum membrane protein. Mol.Biol. Cell 7:2029-44

Hart M, Concordet J-P, Lassot I, Albert I, del los Santos R, et al. 1999. The F-box protein $\beta$-TrCP associates with phosphorylated $\beta$-catenin and regulates its activity in the cell. Curr. Biol. 9:207-10

Hatakeyama S, Kitagawa M, Nakayama K, Shirane M, Matsumoto M, et al. 1999. Ubiquitindependent degradation of $\mathrm{I} \kappa \mathrm{B} \alpha$ is mediated by a ubiquitin ligase Skp1/Cul1/F-box protein FWD1. Proc. Natl. Acad. Sci. USA 96:3859-63

Henchoz S, Chi Y, Catarin B, Herskowitz I, Deshaies RJ, Peter M. 1997. Phosphorylationand ubiquitin-dependent degradation of the 
cyclin-dependent kinase inhibitor Farlp in budding yeast. Genes Dev. 11:3046-60

Hochstrasser M. 1995. Ubiquitin, proteasomes, and the regulation of intracellular protein degradation. Curr. Opin. Cell Biol. 7:215-23

Honda R, Tanaka H, Yasuda H. 1997. Oncoprotein MDM2 is a ubiquitin ligase E3 for tumor suppressor p53. FEBS Lett. 420:25-27

$\mathrm{Hu}$ G, Fearon ER. 1999. Siah-1 N-terminal RING domain is required for proteolysis function, and C-terminal sequences regulate oligomerization and binding to target proteins. Mol. Cell. Biol. 19:724-32

Hubbard E, Wu G, Kitajewski J, Greenwald I. 1997. sel-10, a negative regulator of lin-12 activity in Caenorhabditis elegans, encodes a member of the CDC4 family of proteins. Genes Dev. 11:3182-93

Ingram G, Doyle S, Carpenter R, Schultz E, Simon R, Coen E. 1997. Dual role for fimbriata in regulating floral homeotic genes and cell division in Antirrhinum. EMBO J. 16:652134

Jacquenoud M, Gulli M-P, Peter K, Peter M. 1998. The Cdc42p effector Gic2p is targeted for ubiquitin-dependent degradation by the $\mathrm{SCF}^{\mathrm{Grrl}}$ complex. EMBO J. 17:5360-73

Jallepalli P, Tien D, Kelly T. 1998. sud1+ targets cyclin-dependent kinase-phosphorylated Cdc18 and Rum1 proteins for degradation and stops unwanted diploidization in fission yeast. Proc. Natl. Acad. Sci. USA 95:8159-64

Jiang J, Struhl G. 1998. Regulation of the Hedgehog and Wingless signalling pathways by the F-box/WD40-repeat protein Slimb. Nature 391:493-96

Kaiser P, Sia RA, Bardes EG, Lew DJ, Reed SI. 1998. Cdc34 and the F-box protein Met30 are required for degradation of the Cdk-inhibitory kinase Swe1. Genes Dev. 12: 2587-97

Kamura T, Koepp DM, Conrad MN, Skowyra D, Moreland RJ, et al. 1999. Rbx1, a component of the VHL tumor suppressor complex and SCF ubiquitin ligase. Science 284:65761
Kamura T, Sato S, Haque D, Liu L, Kaelin WG Jr, et al. 1998. The Elongin BC complex interacts with the conserved SOCS-box motif present in members of the SOCS, ras, WD-40 repeat, and ankyrin repeat families. Genes Dev. 12:3872-81

Kaplan KB, Hyman AA, Sorger PK. 1997. Regulating the yeast kinetochore by ubiquitindependent degradation and Skp1p-mediated phosphorylation. Cell 91:491-500

Kibel A, Iliopoulos O, DeCaprio J, Kaelin W. 1995. Binding of the von Hippel-Lindau tumor suppressor protein to Elongin B and C. Science 269:1444-46

Kipreos ET, Lander LE, Wing JP, He WW, Hedgecock EM. 1996. cul-1 is required for cell cycle exit in C. elegans and identifies a novel gene family. Cell 85:1-20

Kishi T, Seno T, Yamao F. 1998. Grr1 functions in the ubiquitin pathway in Saccharomyces cerevisiae through association with Skp1. Mol. Gen. Genet. 257:143-48

Kolman CJ, Toth J, Gonda DK. 1992. Identification of a portable determinant of cell cycle function within the carboxyl-terminal domain of the yeast CDC34 (UBC3) ubiquitin conjugating (E2) enzyme. EMBO J. 11:3081-90

Kominami K-I, Ochotorena I, Toda T. 1998. Two F-box/WD-repeat proteins Pop1 and Pop2 form hetero- and homo-complexes together with cullin-1 in the fission yeast SCF (Skp1-Cullin-1-F-box) ubiquitin ligase. Genes Cells 3:721-35

Kominami K, Toda T. 1997. Fission yeast WDrepeat protein Pop1 regulates genome ploidy through ubiquitin-proteasome-mediated degradation of the CDK inhibitor Rum1 and the S-phase initiator Cdc18. Genes Dev. 11: 1548-60

Kornitzer D, Raboy B, Kulka RG, Fink GR. 1994. Regulated degradation of the transcription factor GCN4. EMBO J. 13:6021-30

Krek W. 1998. Proteolysis and the G1-S transition: the SCF connection. Curr. Opin. Genet. Dev. 8:36-42

Kroll M, Margottin F, Kohl A, Renard P, Durand 
$\mathrm{H}$, et al. 1999. Inducible degradation of $\mathrm{I} \kappa \mathrm{B} \alpha$ by the proteasome requires interaction with the F-box protein h- $\beta$-TrCP. J. Biol. Chem. 274:7941-45

Kumar A, Paietta JV. 1998. An additional role for the F-box motif: gene regulation within the Neurospora crassa sulfur control network. Proc. Natl. Acad. Sci. USA 95:241722

Kwon YT, Reiss Y, Fried VA, Hershko A, Yoon JK, et al. 1998. The mouse and human genes encoding the recognition component of the N-end rule pathway. Proc. Natl. Acad. Sci. USA 95:7898-903

Lambright DG, Sondek J, Bohm A, Skiba NP, Hamm HE, Sigler PB. 1996. The $2.0 \AA$ crystal structure of a heterotrimeric $G$ protein. Nature 379:311-19

Lammer D, Mathias N, Laplaza JM, Jiang W, Liu Y, et al. 1998. Modification of yeast $\mathrm{Cdc53p}$ by the ubiquitin-related protein Rub1p affects function of the $\mathrm{SCF}^{\mathrm{Cdc} 4}$ complex. Genes Dev. 12:914-26

Lanker S, Valdivieso MH, Wittenberg C. 1996. Rapid degradation of the G1 cyclin Cln2 induced by CDK-dependent phosphorylation. Science 271:1597-601

Latres E, Chiaur D, Pagano M. 1999. The human $\mathrm{F}$ box protein $\beta$-Trcp associates with the $\mathrm{Cul1/Skp1} \mathrm{complex} \mathrm{and} \mathrm{regulates} \mathrm{the} \mathrm{stabil-}$ ity of $\beta$-catenin. Oncogene 18:849-54

Lee I, Wolfe D, Nilsson O, Weigel D. 1997. A LEAFY co-regulator encoded by UNUSUAL FLORAL ORGANS. Curr. Biol. 7:95-104

Li FN, Johnston M. 1997. Grr1 of Saccharomyces cerevisiae is connected to the ubiquitin proteolysis machinery through Skp1: coupling glucose sensing to gene expression and the cell cycle. EMBO J. 16:5629-38

Liakopoulos D, Doenges G, Matuschewski K, Jentsch S. 1998. A novel protein modification pathway related to the ubiquitin system. EMBO J. 17:2208-14

Lisztwan J, Marti A, Sutterluty H, Gstaiger M, Wirbelauer C, Krek W. 1998. Association of human CUL-1 and ubiquitin-conjugating enzyme CDC34 with the F-box protein p45(SKP2): evidence for evolutionary conservation in the subunit composition of the CDC34-SCF pathway. EMBO J. 17:368-83

Lonergan KM, Iliopoulos O, Ohh M, Kamura $\mathrm{T}$, Conaway RC, et al. 1998. Regulation of hypoxia-inducible mRNAs by the von Hippel-Lindau tumor suppressor protein requires binding to complexes containing elongins B/C and Cul2. Mol. Cell. Biol. 18:73241

Lyapina S, Correll C, Kipreos E, Deshaies R. 1998. Human CUL1 forms an evolutionarily conserved ubiquitin ligase complex (SCF) with SKP1 and an F-box protein. Proc. Natl. Acad. Sci. USA 95:7451-56

Margottin F, Bour S, Durand H, Selig L, Benichou $S$, et al. 1998. A novel human WD protein, $\mathrm{h} \beta \operatorname{TrCp}$, that interacts with HIV-1 Vpu connects $\mathrm{CD} 4$ to the ER degradation pathway through an F-box motif. Mol. Cell 1:565-74

Marikawa Y, Elinson RP. 1998. $\beta$-TrCP is a negative regulator of $\mathrm{Wnt} / \beta$-catenin signaling pathway and dorsal axis formation in Xenopus embryos. Mech. Dev. 77:75-80

Marti A, Wirbelauer C, Scheffner M, Krek W. 1999. SCFSKP2 ubiquitin ligase/E2F-1 transcription factor complex formation underlies regulation of E2F-1 protein stability and S phase promoting function. Nat. Cell Biol. 1:14-19

Mathias N, Johnson S, Byers B, Goebl M. 1999. The abundance of cell cycle regulatory protein $\mathrm{Cdc} 4 \mathrm{p}$ is controlled by interactions between its F box and Skp1p. Mol. Cell. Biol. 19:1759-67

Mathias N, Johnson SL, Winey M, Adams AE, Goetsch L, et al. 1996. Cdc53 acts in concert with $\mathrm{Cdc} 4$ and $\mathrm{Cdc} 34$ to control the $\mathrm{G} 1$ to $S$ phase transition and identifies a conserved family of proteins. Mol. Cell. Biol. 16:6634 43

Mathias N, Steussy CN, Goebl MG. 1998. An essential domain within $\mathrm{Cdc} 34 \mathrm{p}$ is required for binding to a complex containing Cdc $4 \mathrm{p}$ and Cdc53p in Saccharomyces cerevisiae. J. Biol. Chem. 273:4040-45 
Michael WM, Newport J. 1998. Coupling of mitosis to the completion of $\mathrm{S}$ phase through Cdc34-mediated degradation of Wee1. Science 282:1886-89

Michel JJ, Xiong Y. 1998. Human CUL-1, but not other cullin family members, selectively interacts with SKP1 to form a complex with SKP2 and cyclin A. Cell Growth Diff. 9:43549

Natorff R, Piotrowska M, Paszewski A. 1998. The Aspergillus nidulans sulphur regulatory gene sconB encodes a protein with WD40 repeats and an F-box. Mol. Gen. Genet. 257:255-63

Ng RW, Arooz T, Yam CH, Chan IW, Lau AW, Poon RY. 1998. Characterization of the cullin and F-box protein partner Skp1. FEBS Lett. 438:183-89

Ohta T, Michel JJ, Schottelius AJ, Xiong Y. 1999. ROC1, a homolog of APC11, represents a family of cullin partners with an associated ubiquitin ligase activity. Mol. Cell 3:535-41

Osaka F, Kawasaki H, Aida N, Saeki M, Chiba T, et al. 1998. A new NEDD8-ligating system for cullin-4A. Genes Dev. 12:2263-68

Pagano M, Tam SW, Theodoras AM, BeerRomero P, Del Sal G, et al. 1995. Role of the ubiquitin-proteasome pathway in regulating abundance of the cyclin-dependent kinase inhibitor p27. Science 269:682-85

Patton EE, Willems AR, Sa D, Kuras L, Thomas D, et al. 1998. Cdc53 is a scaffold protein for multiple Cdc34/Skp1/F-box protein complexes that regulate cell division and methionine biosynthesis in yeast. Genes Dev. 12:692-705; (erratum) Genes Dev. 19:3144

Patton EE, Willems AR, Tyers M. 1998a. Combinatorial control in ubiquitin-dependent proteolysis: Don't Skp the F-box hypothesis. Trends Genet. 14:236-43

Pause A, Lee S, Worrell RA, Chen DY, Burgess WH, et al. 1997. The von Hippel-Lindau tumor-suppressor gene product forms a stable complex with human CUL-2, a member of the Cdc53 family of proteins. Proc. Natl. Acad. Sci. USA 94:2156-61
Peterson TA, Yochem J, Byers B, Nunn MF, Duesberg PH, et al. 1984. A relationship between the yeast cell cycle genes $C D C 4$ and $C D C 36$ and the ets sequence of oncogenic virus E26. Nature 309:556-58

Piotrowski J, Beal R, Hoffman L, Wilkinson KD, Cohen RE, Pickart CM. 1997. Inhibition of the $26 \mathrm{~S}$ proteasome by polyubiquitin chains synthesized to have defined lengths. J. Biol. Chem. 272:23712-21

Plon SE, Leppig KA, Do HN, Groudine M. 1993. Cloning of the human homolog of the $C D C 34$ cell cycle gene by complementation in yeast. Proc. Natl. Acad. Sci. USA 90:10484-88

Pringle JR, Hartwell LH. 1981. The Saccharomyces cerevisiae cell cycle. In The Molecular Biology of the Yeast SaccharomycesLife Cycle and Inheritance, ed. JN Strathern, EW Jones, JR Broach. pp. 97-142. Cold Spring Harbor, NY: Cold Spring Harbor Lab. Press

Ptak C, Prendergast JA, Hodgins R, Kay CM, Chau V, Ellison MJ. 1994. Functional and physical characterization of the cell cycle ubiquitin-conjugating enzyme CDC34 (UBC3). Identification of a functional determinant within the tail that facilitates CDC34 self-association. J. Biol. Chem. 269:2653945

Ruegger M, Dewey E, Gray WM, Hobbie L, Turner J, Estelle M. 1998. The TIR1 protein of Arabidopsis functions in auxin response and is related to human SKP2 and yeast Grr1p. Genes Dev. 12:198-207

Scheffner M, Nuber U, Huibregtse JM. 1995. Protein ubiquitination involving an E1-E2E3 enzyme ubiquitin thioester cascade. $\mathrm{Na}$ ture 373:81-83

Schneider BL, Patton EE, Lanker S, Mendenhall MD, Wittenberg C, et al. 1998. Yeast G1 cyclins are unstable in G1 phase. Nature 395:86-89

Schneider BL, Yang QH, Futcher AB. 1996. Linkage of replication to START by the CDK inhibitor Sic1. Science 272:560-62

Schwob E, Böhm T, Mendenhall M, Nasmyth 
K. 1994. The B-type cyclin kinase inhibitor $\mathrm{p} 40^{\mathrm{SIC} 1}$ controls the G1/S transition in Saccharomyces cerevisiae. Cell 79:233-44

Seol J, Feldman R, Zachariae W, Shevchenko A, Correll C, et al. 1999. Cdc53/cullin and the essential Hrt1 RING-H2 subunit of SCF define a ubiquitin ligase module that activates the E2 enzyme Cdc34. Genes Dev. In press

Sheaff RJ, Groudine M, Gordon M, Roberts JM, Clurman BE. 1997. Cyclin E-CDK2 is a regulator of p27Kip1. Genes Dev. 11:1464-78

Sia R, Bardes E,Lew D. 1998. Control of Swe1p degradation by the morphogenesis checkpoint. EMBO J. 17:6678-88

Silver ET, Gwozd TJ, Ptak C, Goebl M, Ellison MJ. 1992. A chimeric ubiquitin conjugating enzyme that combines the cell cycle properties of CDC34 (UBC3) and the DNA repair properties of RAD6 (UBC2): implications for the structure, function and evolution of the E2s. EMBO J. 11:309198

Skowyra D, Craig K, Tyers M, Elledge S, Harper J. 1997. F-box proteins are receptors that recruit phosphorylated substrates to the SCF ubiquitin-ligase complex. Cell 91:20919

Skowyra D, Koepp DM, Kamura T, Conrad MN, Conaway RC, et al. 1999. Reconstitution of G1 cyclin ubiquitination with complexes containing SCFGrr1 and rbx1. Science 284:662-65

Sondek J, Bohm A, Lambright DG, Hamm HE, Sigler PB. 1996. Crystal structure of a $\mathrm{G}$ protein $\beta \gamma$ dimer at 2.1 angstrom resolution. $\mathrm{Na}$ ture 379:369-74

Stebbins C, Kaelin W, Pavletich N. 1999. Structure of the VHL-elongin C-elongin B complex: implications for VHL tumor suppressor function. Science 284:455-61

Stemmann O, Lechner J. 1996. The Saccharomyces cerevisiae kinetochore contains a cyclin-cdk complexing homolog as indentified by in vitro reconstitution. EMBO J. 15:3611-20

Suzuki H, Chiba T, Kobayashi M, Takeuchi M, Suzuki T, et al. 1999. I $\kappa \mathrm{B} \alpha$ ubiquitination is catalyzed by an SCF-like complex containing Skp1, cullin-1 and two F-box/WD4-repeat proteins, $\beta$-TrCP1 and $\beta$-TrCP2. Biochem. Biophys. Res. Comm. 256:127-32

Takagi Y, Conaway RC, Conaway JW. 1996. Characterization of elongin $\mathrm{C}$ functional domains required for interaction with elongin $\mathrm{B}$ and activation of elongin A. J. Biol. Chem. 271:25562-68

Takagi Y, Pause A, Conaway RC, Conaway JW. 1997. Identification of elongin $C$ sequences required for interaction with the von HippelLindau tumor suppressor protein. J. Biol. Chem. 272:27444-49

Tan P, Fuchs SY, Chen A, Wu K, Gomez C, et al. 1999. Recruitment of a ROC1-CUL1 ubiquitin ligase by Skp1 and HOS to catalyze the ubiquitination of $\mathrm{I} \kappa \mathrm{B} \alpha$. Mol. Cell 3:527-33

Teng-umnuay P, Morris HR, Dell A, Panico M, Paxton T, West CM. 1998. The cytoplasmic F-box binding protein SKP1 contains a novel pentasaccharide linked to hydroxyproline in Dictyostelium. J. Biol. Chem. 273:18242-49 Theodosiou NA, Zhang S, Wang WY, Xu T. 1998. slimb coordinates wg and dpp expression in the dorsal-ventral and anteriorposterior axes during limb development. $D e$ velopment 125:3411-16

Verma R, Annan RS, Huddleston MJ, Carr SA, Reynard G, Deshaies RJ. 1997a. Phosphorylation of Sic1p by G1 Cdk required for its degradation and entry into $\mathrm{S}$ phase. Science 278:455-60

Verma R, Feldman R, Deshaies RJ. 1997b. SIC1 is ubiquitinated in vitro by a pathway that requires CDC4, CDC34, and cyclin/CDK activities. Mol. Biol. Cell. 8:1427-37

Wada H, Yeh E, Kamitani T. 1999. Identification of NEDD8-conjugation site in human cullin-2. Biochem. Biophys. Res. Comm. 257:100-5

Wall MA, Coleman DE, Lee E, Iniguez-Llhui JA, Posner BA, et al. 1995. The structure of the $\mathrm{G}$ protein heterotrimer $\mathrm{G}_{\mathrm{i}} \alpha_{1} \beta_{1} \gamma_{2}$. Cell 83:1047-58

Willems AR, Lanker S, Patton EE, Craig KL, Nason TF, et al. 1996. Cdc53 targets 
phosphorylated G1 cyclins for degradation by the ubiquitin proteolytic pathway. Cell 86:453-63

Wolf D, McKeon F, Jackson P. 1999. F-box/WD-repeat proteins Pop1p and Sud1p/ Pop2p form complexes that bind and direct the proteolysis of Cdc18p. Curr. Biol. 9:373-76

Xie DX, Feys BF, James S, Nieto-Rostro M, Turner JG. 1998. COI1: an Arabidopsis gene required for jasmonate-regulated defense and fertility. Science 280:1091-94

Yaglom J, Linskens MHK, Sadis S, Rubin DM, Futcher B, Finley D. 1995. p34 Cdc28. mediated control of CLN3 cyclin degradation. Mol. Cell. Biol. 15:731-41

Yam CH, Ng RWM, Yi Siu W, Lau AWS, Poon RYC. 1999. Regulation of cyclin A-cdk2 by SCF component Skp1 and F-Box protein Skp2. Mol. Cell. Biol. 19:635-45

Yaron A, Hatzubai A, Davis M, Lavon I, Amit $\mathrm{S}$, et al. 1998. Identification of the receptor component of the $\mathrm{I} \kappa \mathrm{B} \alpha$-ubiquitin ligase. $\mathrm{Na}$ ture 396:590-94

Yew PR, Kirschner MW. 1997. Proteolysis and DNA replication: the CDC34 requirement in the Xenopus egg cell cycle. Science 277:1672-76

Yu H, Peters JM, King RW, Page AM, Hie- ter P, Kirschner MW. 1998. Identification of a cullin homology region in a subunit of the anaphase-promoting complex. Science 279:1219-22

Yu Z-K, Gervais J, Zhang H. 1998. Human CUL-1 associates with the SKP1/SKP2 complex and regulates p21CIP1/WAF1 and cyclin D proteins. Proc. Natl. Acad. Sci. USA 95:11324-29

Zachariae W, Shevchenko A, Andrews PD, Ciosk R, Galova M, et al. 1998. Mass spectrometric analysis of the anaphase-promoting complex from yeast: identification of a subunit related to cullins. Science 279:121619

Zhang H, Kobayashi R, Galaktionov K, Beach D. 1995. p19(SKP1) and p45(SKP2) are essential elements of the cyclin A-CDK2 S phase kinase. Cell 82:912-25

Zhang J-G, Farley A, Nicholson S, Willson T, Zugaro L, et al. 1999. The conserved SOCS box motif in suppressors of cytokine signaling binds to elongins $\mathrm{B}$ and $\mathrm{C}$ and may couple bound proteins to proteasomal degradation. Proc. Natl. Acad. Sci. USA 96:2071-76

Zhou P, Howley PM. 1998. Ubiquitination and degradation of the substrate recognition subunits of SCF ubiquitin-protein ligases. Mol. Cell 2:571-80 
AR Annual Review of Cell and Developmental Biology

\section{CONTENTS}

Vacuolar Import of Proteins and Organelles from the Cytoplasm, Daniel J. Klionsky, Yoshinori Ohsumi

1

Blue-Light Photoreceptors In Higher Plants, Winslow R. Briggs, Eva

Huala

Cooperation Between Microtubule- and Actin-Based Motor Proteins, Susan S. Brown

Molecular Mechanisms of Neural Crest Formation, Carole LaBonne, Marianne Bronner-Fraser

Lymphocyte Survival--The Struggle Against Death, Robert H. Arch,

Craig B. Thompson

The Road Less Traveled: Emerging Principles of Kinesin Motor Utilization, Lawrence S. B. Goldstein, Alastair Valentine Philp

Proteins of the ADF/Cofilin Family: Essential Regulators of Actin Dynamics, James R. Bamburg

Visual Transduction in Drosophila, Craig Montell

Biochemical Pathways of Caspases Activation During Apoptosis, Imawati Budihardjo, Holt Oliver, Michael Lutter, Xu Luo, Xiaodong Wang

Regulation of Nuclear Localization: A Key to a Door, Arie Kaffman, Erin K. O'Shea

Actin-Related Proteins, D. A. Schafer, T. A. Schroer

Cell Polarity in Yeast, John Chant

Vertebrate Endoderm Development, James M. Wells, Douglas A. Melton

Neural Induction, Daniel C. Weinstein, Ali Hemmati-Brivanlou

411

SCF and CDC53/Cullin-Based Ubiquitin Ligases, R. J. Deshaies

435

Integration of Signaling Networks that Regulate Dictyostelium

Differentiation, Laurence Aubry, Richard Firtel

When to Switch to Flowering, Gordon G. Simpson, Anthony R. Gendall, Caroline Dean

Regulation of Mammalian O2 Homeostasis by Hypoxia-Inducible Factor 1, Gregg L. Semenza

Mechanisms of Viral Interference with MHC Class I Antigen Processing and Presentation, Jonathan W. Yewdell, Jack R. Bennink

Transport Between the Cell Nucleus and the Cytoplasm, Dirk Görlich, Ulrike Kutay 
[PSI+]: An Epigenetic Modulator of Translation Termination Efficiency,

Tricia R. Serio, Susan L. Lindquist

Adaptors for Clathrin-Mediated Traffic, Tomas Kirchhausen

Synaptic Vesicle Biogenesis, Matthew J. Hannah, Anne A. Schmidt,

Wieland B. Huttner

The Translocon: A Dynamic Gateway at the ER Membrane, Arthur E. Johnson, Michael A. van Waes 